\title{
Why Do Adolescents Use Maladaptive Emotion Regulation Strategies? The Role of Perceived Effectiveness, Distress Tolerance, and Impulsivity
}

\author{
Karena M. Moran
}

Follow this and additional works at: https://researchrepository.wvu.edu/etd

\footnotetext{
Recommended Citation

Moran, Karena M., "Why Do Adolescents Use Maladaptive Emotion Regulation Strategies? The Role of Perceived Effectiveness, Distress Tolerance, and Impulsivity" (2016). Graduate Theses, Dissertations, and Problem Reports. 6256.

https://researchrepository.wvu.edu/etd/6256

This Thesis is protected by copyright and/or related rights. It has been brought to you by the The Research Repository @ WVU with permission from the rights-holder(s). You are free to use this Thesis in any way that is permitted by the copyright and related rights legislation that applies to your use. For other uses you must obtain permission from the rights-holder(s) directly, unless additional rights are indicated by a Creative Commons license in the record and/ or on the work itself. This Thesis has been accepted for inclusion in WVU Graduate Theses, Dissertations, and Problem Reports collection by an authorized administrator of The Research Repository @ WVU. For more information, please contact researchrepository@mail.wvu.edu.
} 
Why Do Adolescents Use Maladaptive Emotion Regulation Strategies? The Role of Perceived Effectiveness, Distress Tolerance, and Impulsivity

Karena M. Moran, B.A.

Thesis submitted to the Eberly College of Arts and Sciences at West Virginia University in partial fulfillment of the requirements for the degree of

Master of Science

in Psychology

\author{
Amy Gentzler, Ph.D. Chair \\ Aaron Metzger, Ph.D. \\ Barry Edelstein, Ph.D. \\ Department of Psychology \\ Morgantown, West Virginia \\ 2016
}

Keywords: adolescence, emotion beliefs, emotion regulation, perceived effectiveness

Copyright 2016 Karena M. Moran 


\begin{abstract}
Why Do Adolescents Use Maladaptive Emotion Regulation Strategies? The Role of Perceived Effectiveness, Distress Tolerance, and Impulsivity

Karena M. Moran

Much is known about outcomes associated with adaptive and maladaptive emotion regulation strategies. However, less research has explored predictors of strategy use. The present study examined perceived effectiveness of strategies (i.e., how effective individuals believe a strategy is at decreasing negative affect or increasing positive affect) as a predictor of strategy use. The sample of 139 adolescents $\left(M_{\text {age }}=15.50,60.4 \%\right.$ male $)$ reported their use of regulatory strategies for positive and negative emotions and how effective they believed each strategy was at changing their emotional state in the desired direction (i.e., more positive, less negative). Strategies were aggregated into adaptive and maladaptive scales for each affective type. Covarying age and gender, four hierarchical linear regression models revealed that perceived effectiveness was significantly associated with strategy use. These findings indicate that adolescents' perceived effectiveness of strategies is a strong predictor of strategy use, which may have important educational and clinical implications.
\end{abstract}

Keywords: adolescence, emotion beliefs, emotion regulation, perceived effectiveness 


\section{TABLE OF CONTENTS}

I. Introduction (pp. 1-4)

II. Method (pp. 5-9)
a. Participants (pp. 5)
b. Procedure (pp. 5-6)
c. Measures (pp. 6-9)

III. Results (pp. 9-11)
a. Preliminary Analyses (pp. 9-10)
b. Primary Analyses (pp.10-11)

IV. Discussion (pp. 11-14)

V. References (pp. 15-19)

VI. Table 1: Descriptive Statistics and Bivariate Correlations between Perceived Effectiveness and Use of Emotion Regulation Strategies (pp. 20)

VII. Table 2: Hierarchical Linear Regression Models (pp. 21)

VIII. Appendices (pp. 22-66)

a. Appendix A: Distress Tolerance and Impulsivity (pp. 23-57)

i. Introduction (pp. 23-33)

ii. Method (pp. 33-35)

1. Participants (pp. 33-34)

2. Procedure (pp. 34)

3. Measures (pp. 34-35)

iii. Results and Discussion (pp. 35-46)

1. Preliminary Analyses (pp. 35-36)

2. Primary Analyses (pp. 36-43) 
iv. Full Discussion (pp. 43-46)

v. References (pp. 47-53)

vi. Table A1: Descriptive Statistics and Bivariate Correlations between

Distress Tolerance, Impulsivity, and Use of Emotion Regulation Strategies (pp. 54)

vii. Table A2: Moderation Models (pp. 55)

viii. Figure A1: Proposed Structural Equation Model (pp. 56)

ix. Figure A2: Trimmed Structural Equation Model (pp. 57)

b. Appendix B: Demographic Measures (pp. 58-59)

c. Appendix C: Questionnaire Measures (pp. 60-66) 
Why Did You Do That? Because I Thought It Would Work! The Role of Perceived Effectiveness in Adolescent Emotion Regulation

Emotions are a critical component of human life. While emotions have adaptive functions (e.g., facilitate decision-making), they also often require regulation (Gross, 1998b). Thus, emotion regulation (ER), often defined as "the processes by which individuals influence which emotions they have, when they have them, and how they experience and express these emotions" (Gross, 1998b, p. 275), is an essential area of research. Research in this area has mainly focused on the outcomes associated with ER (e.g., psychopathology; Aldao, Nolen-Hoeksema, \& Schweizer, 2010), whereas less is known about predictors. Examining predictors of ER is important because ER has been considered an important factor for mental health (Gross \& Munoz, 1995; Şimşek \& Çerçi, 2013), and it may be especially important during adolescence given that emotions may be particularly intense during this period (Arnett, 2002; Larson, Moneta, Richards, \& Wilson, 2002). To better understand adolescents' ER, the present study examined perceived effectiveness as a potential reason some adolescents are more likely than others to use maladaptive strategies to regulate negative affect (NA) and positive affect (PA). We propose that if adolescents believe a strategy is effective, or going to change their emotion in the desired direction (i.e., less negative or more positive), they will be more likely to use that strategy to regulate their emotions.

\section{Adaptive and Maladaptive Emotion Regulation}

Regulatory strategies are generally regarded as adaptive or maladaptive based on their association with positive or negative outcomes. The findings are relatively consistent in terms of classifying strategies as adaptive or maladaptive (Aldao \& Nolen-Hoeksema, 2012; Augustine \& 
Hemenover, 2009), even though emotions should be viewed as adaptive or effective within particular contexts (Aldao \& Nolen-Hoeksema, 2012; Aldao, 2013).

Adaptive ER strategies with NA are those that show negative associations with psychopathology (Aldao et al., 2010; Aldao \& Nolen-Hoeksema, 2012) and positive relations to outcomes such as well-being (Gross \& John, 2003). Strategies such as problem solving (i.e., thinking about how to handle the event), distraction (i.e., thinking about or doing something else), support-seeking (i.e., telling someone about the problem or feelings), and reappraisal (i.e., construing the situation in a different way) have been considered adaptive ER strategies with NA (Aldao et al., 2010; Augustine \& Hemenover, 2009; Gross \& John, 2003; Webb, Miles, \& Sheeran, 2012). The direct effectiveness of ER strategies (i.e., how successful a strategy is at decreasing, increasing, or maintaining emotional intensity; Sheppes \& Gross, 2012) with NA has been explored extensively, most often in lab studies (see Augustine \& Hemenover, 2009 and Webb et al., 2012 for reviews). These experimental studies are generally consistent with correlational work, suggesting that certain strategies (e.g., reappraisal) are more effective at decreasing the overall experience of NA than others (e.g., suppression; Gross, 1998a).

Conversely, maladaptive ER strategies with have been positively associated with negative outcomes (e.g., psychopathology; Aldao et al., 2010). Strategies such as avoidance (i.e., avoiding thoughts or experiences of emotion), rumination (i.e., repeatedly focusing on the event or emotion), venting (i.e., overt expressions of emotion), and suppression (i.e., avoiding any display of emotion) are considered maladaptive forms of ER with NA (Aldao \& NolenHoeksema, 2012; Augustine \& Hemenover, 2009; Feldman, Joormann, \& Johnson, 2008; Webb et al., 2012). In experimental research, maladaptive strategies (e.g., suppression) are those that are not effective at decreasing the experience of NA (Gross, 1998a). While suppression does 
decrease outward facial expressions of negative emotions, it has shown to increase physiological responding (e.g., sympathetic activation; Gross \& John, 2003; Gross, 1998a), suggesting it is not successful in decreasing emotional arousal.

Research regarding the regulation of PA is understudied in comparison to NA, however a general pattern of strategies' adaptiveness has emerged. Specifically, savoring, maximizing, and capitalizing strategies that up-regulate or increase positive emotions are considered adaptive forms of ER with PA (e.g., reflecting on positive emotions; Bijttebier, Raes, Vasey, \& Feldman, 2012; Bryant, 2003; Gentzler, Morey, Palmer, \& Yi, 2012; Livingstone \& Srivastava, 2012). In contrast, dampening and minimizing strategies that down-regulate or decrease PA have been considered maladaptive regulatory strategies with positive emotions (e.g., think about things that could go wrong; Feldman et al., 2008). The direct effectiveness of ER strategies with PA has been explored less often. Recently, Quoidbach, Mikolajczak, and Gross (2015), compiled a review of studies focusing on positive ER interventions and their effectiveness. Strong evidence supports the effectiveness of attentional deployment (e.g., savoring the moment), cognitive change (e.g., think about how lucky you are), and response modulation (e.g., expressing PA; Quoidbach et al., 2015). However, more experimental work is needed on positive ER.

\section{Perceived Effectiveness and Emotion Regulation}

Although studies have investigated the adaptiveness and direct effectiveness of ER strategies, few studies have examined participants' perceived effectiveness of the same strategies (i.e., how effective the individual believes a strategy is at decreasing, increasing, or maintaining emotional intensity). In one recent exception, perceived effectiveness of ER strategies for anger and sadness were examined in elementary-aged children though not in relation to the children's use of ER strategies (Waters \& Thompson, 2014). The results indicated that children who rated a 
strategy as effective for anger, tended to rate the same strategy as effective for sadness (e.g., venting emotions). However, other strategies were endorsed as especially effective for anger (e.g., problem solving) or sadness (e.g., seek adult support), suggesting that at these ages there is some emotion specificity in perceived effectiveness of strategies. Another recent study used an experience sampling method to examine ER in college-aged participants. Interestingly, collegeaged participants' self-reported perception of a strategy's impact on emotional intensity did not directly relate to their actual reported change in mood (Heiy \& Cheavens, 2014). This finding suggests that individuals may use a strategy because they believe it is effective, but in reality the strategy does not change the way they feel. Other research in a different domain (engagement in risky activities), has indicated that adolescents who engage in risky activities perceive the activities as more beneficial and less risky than adolescents who do not engage in these behaviors (Zimmermann, 2010). Moreover, the most powerful predictor of engagement in risk behavior is perceived benefit (compared to sensation seeking, gender, and age; Zimmermann, 2010). Overall, this limited research suggests that believing an ER strategy would be effective or change one's affect in the anticipated direction (i.e., lower NA, greater PA) may predict greater use of that strategy.

\section{The Present Study}

The present study examined the association between perceived effectiveness and use of ER strategies across adaptive and maladaptive strategies for positive and negative emotions. Based on previous research with risk behavior, it was hypothesized that adolescents' perceived effectiveness of a strategy would be positively related to their use of the same strategy. We believed this association would hold across all types of strategies: adaptive and maladaptive strategies with positive and negative affect. 


\section{Method}

\section{Participants}

Participants were 139 adolescents ranging from 14 to 18 years old $(M=15.50, S D=.89$; $60.4 \%$ male). The participants reflected the socio-demographic characteristics of the areas from which they were recruited. Specifically, $79.9 \%$ of the sample self-identified as White/Caucasian, 9.4\% as African-American, 5.6\% as other or multiple ethnicities, 2.9\% as Asian or AsianAmerican, $1.4 \%$ as Hispanic/Latin-American, and .7\% as Pacific-Islander or Native Hawaiian. Eighty percent of adolescents also had at least one caregiver participate. Of the participating caregivers, the majority reported that adolescents resided in homes with two parents present (84.1\%). Most caregivers reported upper-middle class annual incomes (76\% earn $\$ 80,000$ or more), and were well-educated. The majority of caregivers had completed a 4-year degree (28.9\% of mothers; $40 \%$ of fathers) or a Master's or 2-3-year graduate degree $(30.9 \%$ of mothers; $29.1 \%$ of fathers). The sample of 139 was from derived from a larger sample of 143 adolescents recruited from high schools in the North Eastern U.S. as part of a larger study. Four participants were excluded due to patterned responding $(n=1)$ and incomplete data $(n=3)$.

\section{Procedure}

An overview letter of the study, a caregiver contact information form, and an informed consent form for caregivers were distributed in two high schools. For adolescents with caregiver consent, surveys were administered during a designated time at school. Assent was collected from the adolescents and they were given approximately 45 minutes to complete the survey. They received \$20. Eighty percent of adolescents also had at least one caregiver complete a survey (either online or on paper) afterwards. Caregivers also received $\$ 20$ for their 
participation. However, only the adolescent portion of this study is relevant to the current paper and caregiver data will not be discussed further.

\section{Measures}

Use of emotion regulation strategies with negative affect. To assess ER strategies with NA, the Emotion Regulation Questionnaire for Children and Adolescents (ERQ-CA; Gullone \& Taffe, 2012), a modified version of the Emotion Regulation Questionnaire (Gross \& John, 2003), was used. Adolescents reported their use of cognitive reappraisal and expressive suppression as forms of ER with NA. An example reappraisal item is "When I want to feel less bad (e.g., sad, angry, or worried), I think about something different." and an example suppression item is "I control my feelings by not showing them." The ERQ-CA reappraisal and suppression scales have shown good reliability in the past $(\alpha=.82-.86$ and $\alpha=.69-.79$, respectively) as well as sound test-retest reliability over a 12 -month period (reappraisal ICC $=.37-.47$, suppression ICC $=.40$ .63; Gullone \& Taffe, 2012). To assess ER strategies beyond reappraisal and suppression, six items were created to examine support-seeking, avoidance, distraction, rumination, problemsolving, and venting (based on Gentzler et al., 2012). An example item from this scale is: "I talk to someone about my negative feelings or the problem." Each item was rated on a 7-point Likerttype scale $(1=$ Strongly disagree to $7=$ Strongly agree $)$.

Items from the ERQ-CA and the six individual items were aggregated to create two scales: Use of Adaptive ER with NA and Use of Maladaptive ER with NA. The adaptive scale contained six reappraisal items from the ERQ-CA along with the single items support-seeking, distraction, and problem-solving $(\alpha=.79)$. The maladaptive scale contained four suppression items from the ERQ-CA, as well as the single items avoidance, rumination, and venting ( $\alpha=$ 
.68). Higher scores on these scales indicate that the adolescent reported greater use of that strategy type.

\section{Perceived effectiveness of emotion regulation strategies with negative affect.}

Adolescents then reported their perceived effectiveness of each strategy, operationalized as the way in which they think the use of each particular strategy changes their NA (Think about when you have responded in these ways when feeling UPSET or BAD. If you don't respond in these ways, try to imagine how these responses may or may not change how you feel. How would each response change how you feel when feeling UPSET or BAD?). This scale consists of 12 items regarding adolescents' perceived effectiveness of ER strategies with NA (three reappraisal and three suppression items from the ERQ-CA and a single item of each of the other NA regulation strategies). Responses were rated using a 5-point Likert-type scale (1 = Makes me feel really bad [or a lot worse], 2 = Makes me feel a little bad or worse, 3 = Does not change how Ifeel or unsure, 4 = Makes me feel a little good or better, 5 = Makes me feel really good [or a lot better]).

Similar to the ER strategy use scales, perceived effectiveness items were separated into two scales. The Perceived Effectiveness of Adaptive ER with NA scale consists of three reappraisal items, as well as sharing, distraction, and problem-solving $(\alpha=.70)$. The Perceived Effectiveness of Maladaptive ER with NA scale consists of three suppression items along with avoidance, rumination, and venting $(\alpha=.61)$. Higher scores on these scales indicate that the adolescent thinks the strategy is effective and makes them feel better (i.e., down-regulates their NA), whereas lower scores indicate that the strategy is ineffective and makes them feel worse (i.e., up-regulates their NA). 
Use of emotion regulation strategies with positive affect. Next, adolescents reported how likely they are to use specific strategies to regulate PA using the Positive Affect and Responses Survey (PAARS). This scale is an adapted version of other scales (i.e., the Positive Events and Responses Survey for Youth, PEARS-Y, which includes hypothetical vignettes; Gentzler \& Palmer, 2014, and event-specific savoring and dampening scales; Gentzler et al., 2012). However, the version used in the current study (PAARS) was modified to measure general experience of PA. Specifically, it includes 17 items regarding adolescents' use of ER strategies to up-regulate or down-regulate PA and is rated on a 5-point Likert-type scale $(1=$ Not at all likely to $5=$ Very likely).

Similar to previous measures, the PAARS consists of two scales: Use of Adaptive ER with PA (i.e., strategies that sustain or up-regulate PA) and Use of Maladaptive ER with PA (i.e., strategies that down-regulate PA). In the PAARS, the adaptive scale is made up of 12 items $(\alpha=$ .79; e.g., When you are feeling really good and happy, how likely are you to...think about how good you feel?") and the maladaptive scale consists of five items $(\alpha=.47 ;$ " ... think about how things could go wrong?"). Higher scores indicate that the adolescent is more likely to use that strategy type.

Perceived effectiveness of emotion regulation strategies with positive affect. Finally, adolescents reported how they think the use of a particular strategy changes their PA (Think about when you have responded in these ways when feeling GOOD or HAPPY. If you don't respond in these ways, try to imagine how these responses may or may not change how you feel. How do you think each response would change how you feel?). This scale includes 17 items regarding adolescents' perceived effectiveness of ER strategies with PA and is rated using a 5- 
point Likert-type scale $(1=$ Makes me feel really bad [or a lot worse] to $5=$ Makes me feel really good [or a lot better]).

Similar to the PAARS, the perceived effectiveness of ER strategies for PA measure consists of two scales. The Perceived Effectiveness of Adaptive ER with PA scale is made up of 12 items $(\alpha=.79)$, whereas the Perceived Effectiveness of Maladaptive ER with PA scale consists of five items $(\alpha=.66)$. Higher scores indicate that the adolescent thinks the strategy is effective and makes them feel better (i.e., maintains or up-regulates PA), while lower scores indicate that the strategy is ineffective and makes them feel worse (i.e., down-regulates PA).

\section{Results}

\section{Preliminary Analysis}

To create the scales for each variable, participants were required to have $80 \%$ of the items completed. If $80 \%$ of the items were not completed, participants did not receive a score for that particular scale. A square root transformation was performed on the Perceived Effectiveness of Adaptive ER with PA scale to reduce significant skewness. All Use and Perceived Effectiveness variables were standardized to z-scores to ease interpretation of measures with unequal scaling. Transformed and standardized variables were used in all subsequent analyses. One participant was indicated as an outlier on the Use of Adaptive ER with NA scale by a Mahalanobis distance greater than 16.27 as determined by chi-square with three degrees of freedom and p-value less than .001 and was excluded from analyses with Use of Adaptive ER with NA.

The main study variables' means, standard deviations, and bivariate correlations are presented in Table 1. Perceived effectiveness of ER strategies was moderately correlated with use of the same type of strategy in all cases ( $r s$ ranging from .33 to .54). Age and gender effects also were examined. Age was significantly correlated with Use of Adaptive ER with PA ( $r=$ 
.20), suggesting older adolescents up-regulate PA more than younger adolescents. Independent samples $t$-tests revealed two significant gender differences. For Perceived Effectiveness of Maladaptive ER with PA, males reported greater perceived effectiveness than $(M=2.64, S D=$ $.52)$ females $(M=2.17, S D=.55), t(136)=5.09, p<.001$. For Perceived Effectiveness of Maladaptive ER with NA, males $(M=2.85, S D=.52)$ reported greater perceived effectiveness than females $(M=2.42, S D=.67), t(95.9)=4.05, p<.001$.

\section{Primary Analysis}

Four hierarchical linear regression models were performed to examine the associations among perceived effectiveness of ER strategies and use of those strategies (see Table 2). Although age was the only demographic variable found to be correlated with any of the outcome variables in the present study, previous research has shown that adolescent use of ER strategies varies by both age and gender (e.g., Waters \& Thompson, 2014). Therefore, in step one of each analysis, age and gender were covaried. In the second step of each model, perceived effectiveness of the corresponding type of ER strategy was entered. Since all participants did not have complete data on all scales of interest, listwise deletion was utilized in all primary analyses.

In the first model predicting Use of Maladaptive ER with NA, the full model was significant (see Table $2, R^{2}=.11$ ). Age and gender did not significantly predict use of maladaptive strategies. However, in line with hypotheses, Perceived Effectiveness of Maladaptive ER with NA was significantly associated with greater use of maladaptive ER strategies with NA.

In the second model predicting Use of Adaptive ER with NA, the full model accounted for $36 \%$ of the variance. Neither age, nor gender were significant. In line with predictions, 
Perceived Effectiveness of Adaptive ER with NA was strongly associated with adaptive strategy use.

In the third model predicting likelihood of using Maladaptive ER with PA, the full model was significant, $R^{2}=.23$. Gender was a significant predictor with girls reporting greater use of Maladaptive ER strategies with PA on Step 1 and Perceived Effectiveness of Maladaptive ER with PA significantly related to greater use of Maladaptive ER strategies with PA on Step 2.

In the fourth and final model predicting the likelihood of using Adaptive ER with PA, the full model accounted for $33 \%$ of the variance. Age and gender were significant. Specifically, Step 1 indicated that older adolescents and girls regulate positive emotions by up-regulating more than younger adolescents and boys. In line with hypotheses, Perceived Effectiveness of Adaptive ER with PA was related to greater use of adaptive strategies.

\section{Discussion}

The current study revealed that adolescents who perceive ER strategies as effective are more likely to use those strategies to regulate positive and negative emotions, regardless of whether the strategy is adaptive or maladaptive. This finding implies that adolescents' perceptions are important and may play a large role in how they regulate their emotions. Because effects were found for the use of maladaptive ER strategies, these findings have important implications for prevention given that individuals with or at high-risk for psychopathology tend to use less effective ER strategies (Şimşek \& Çerçi, 2013). Our findings suggest these adolescents may believe that those strategies change their affect in desired ways (i.e., decrease NA, increase PA). This research also investigated the regulation of PA, which is less often studied, but still critical to understand (Feldman et al., 2008). 
Following all proposed hypotheses, perceived effectiveness was strongly associated with ER strategy use in each model presented above. Adolescent perceptions have proven to be an important predictor in other areas of research as well (e.g., engagement in risk behavior, Zimmermann, 2010). However, research on ER has only begun to explore the role of perceived effectiveness. Other work with emotions has shown that beliefs about emotions are important (e.g., implicit theories suggest believing emotions are malleable is positively associated with well-being and adjustment; Tamir, John, Srivastava, \& Gross, 2007). Research also suggests that knowledge about emotions and how to manage them effectively is a critical component of emotional intelligence which is similarly predictive of positive outcomes (Mayer, Roberts, \& Barsade, 2008).

Some existing educational programs do teach youth adaptive ER and coping skills. For example, a recent meta-analysis suggests that the implementation of school-based Social and Emotional Learning (SEL) programs show significant improvement in social-emotional competences (Durlak, Weissberg, Dymnicki, Taylor, \& Schellinger, 2011). Many SEL programs focus on preschool and elementary-aged children (87\%; Durlak et al., 2011). However, programs such as RULER (Recognizing, Understanding, Labeling, Expressing, and Regulating Emotions; Brackett \& Rivers, in press) have begun to adapt their programs to middle and high school-aged adolescents. While specific programs focus on a slightly different overall skill-set, self-control and effective regulation of emotions are core competencies in SEL (Durlak et al., 2011). Our study suggests that these programs could benefit from focusing on adolescents' existing beliefs about perceived effectiveness of different ER strategies and teaching them which strategies are more or less effective. A number of clinical approaches also aim to teach effective ER in treatment of psychopathology. For instance, Acceptance and Commitment Therapy (ACT) 
focuses on teaching clients to accept and experience their emotions as they come and go in daily life (Blackledge \& Hayes, 2001). Furthermore, Berking, Wirtz, Svaldi, and Hofmann (2014), have shown that ER training enhanced the positive outcomes associated with Cognitive Behavioral Therapy by replacing standard parts of the therapy with training focused on effective ER skills. This study suggests that perceptions about the effectiveness of ER strategies are another important belief that may be a beneficial subcomponent of emotional intelligence and addition to therapies that aim to teach effective ER.

\section{Limitations and Future Directions}

Although the present study presents a promising first step in research on perceived effectiveness of ER strategies, there are limitations. First, the current study utilized a predominately upper-class, White sample of adolescents. For the present findings to be generalizable, replication with a more ethnically and socioeconomically diverse sample is necessary. The present study was also cross-sectional in nature. Therefore, longitudinal research is needed to determine the direction of effects. For instance, does perceived effectiveness predict the use of ER strategies over time? It also may be that perceived effectiveness and use of ER strategies exhibit a bidirectional association such that individuals use the strategies they believe to be effective as well as individuals perceive a strategy as more or less effective after using it. Even more critical is that perhaps the strategies we deem maladaptive based on the literature, do work for these adolescents (e.g., maybe some adolescents have become adept at avoidance such that it does work to make them feel better). Moreover, we defined effective as decreasing NA and increasing PA. It is possible these "maladaptive strategies" serve the intended purpose for youth who are pursuing contra-hedonic states. For instance, adolescents report higher levels of contra-hedonic motives than adults (i.e., wanting to enhance or maintain NA or dampen PA; 
Riediger, Schmiedek, Wagner, \& Lindenberger, 2009), suggesting that sometimes adolescents want to feel bad. However, even with potential contra-hedonic goals, this study indicated that adolescents more often use strategies that they think will make them feel less NA or more PA. As is common in ER research, the current study aggregated strategies into scales for positive and negative emotions. However, previous research has shown that it may be beneficial to examine ER strategy use for specific emotions (e.g., Heiy \& Cheavens, 2014; Waters \& Thompson, 2014). Furthermore, it may also be beneficial to examine the association between individual strategies and perceived effectiveness of that strategy rather than aggregating by adaptive and maladaptive strategies (Heiy \& Cheavens, 2014). There may be differences in both use and perceived effectiveness of individual strategies for particular emotions that cannot be recognized in these aggregations.

The current study constitutes a preliminary step in exploring the construct of perceived effectiveness in relation to ER strategy use. Future research should further explore perceptions of ER strategies' effectiveness in comparison to other predictors of strategy use (e.g., temperament; Calkins \& Hill, 2007). In general, longitudinal research is needed to understand the formation of ER beliefs (e.g., when are they formed and what predicts them) and bidirectional effects with actual emotional outcomes. It may also be especially beneficial to examine the developmental trajectory of perceptions about the effectiveness of ER strategies. 


\section{References}

Aldao, A. (2013). The future of emotion regulation research: Capturing context. Perspectives on Psychological Science, 8(2), 155-172. doi:10.1177/1745691612459518

Aldao, A. \& Nolen-Hoeksema, S. (2012). When are adaptive strategies most predictive of psychopathology? Journal of Abnormal Psychology, 121(1), 276-281. doi:10.1037/a0023598

Aldao, A., Nolen-Hoeksema, S., \& Schweizer, S. (2010). Emotion-regulation strategies across psychopathology: A meta-analytic review. Clinical Psychology Review, 30(2), 217-37. doi:10.1016/j.cpr.2009.11.004

Arnett, J. J. (2002). Adolescent Storm and Stress, Reconsidered. In J. J. Arnett (Ed.), Readings on Adolescence and Emerging Adulthood (pp. 6-16). Upper Saddle River, NJ: Pearson Education, Inc.

Augustine, A. A. \& Hemenover, S. H. (2009). On the relative effectiveness of affect regulation strategies: A meta-analysis. Cognition \& Emotion, 23(6), 1181-1220. doi:10.1080/02699930802396556

Berking, M., Wirtz, C. M., Svaldi, J., \& Hofmann, S. G. (2014). Emotion regulation predicts symptoms of depression over five years. Behaviour Research and Therapy, 57, 13-20. doi:10.1016/j.brat.2014.03.003

Bijttebier, P., Raes, F., Vasey, M. W., \& Feldman, G. C. (2012). Responses to positive affect predict mood symptoms in children under conditions of stress: A prospective study. Journal of Abnormal Child Psychology, 40(3), 381-389. doi:10.1007/s10802-011-9579-2

Blackledge, J. T. \& Hayes, S. C. (2001). Emotion Regulation in Acceptance and Commitment Therapy. Journal of Clinical Psychology, 57(2), 243-255. 
Brackett, M. A. \& Rivers, S. E. (in press). Transforming Students' Lives with Social and Emotional Learning. Handbook of Emotions in Education, 1-22. doi:10.4324/9780203148211.ch19

Bryant, F. (2003). Savoring Beliefs Inventory (SBI): A scale for measuring beliefs about savouring. Journal of Mental Health, 12(2), 175-196.

doi:10.1080/0963823031000103489

Calkins, S. D. \& Hill, A. (2007). Caregiver influences on emerging emotion regulation: Biological and environmental transactions in early development. In J. J. Gross (Ed.), Handbook of Emotion Regulation (1st ed., pp. 229-248). New York, NY, NY: Guilford Press.

Durlak, J. A., Weissberg, R. P., Dymnicki, A. B., Taylor, R. D., \& Schellinger, K. B. (2011). The impact of enhacing students' social and emotional learning: A meta-analysis of schoolbased universal interventions. Child Development, 82(1), 405-432. doi:10.1111/j.14678624.2010.01564.x

Feldman, G. C., Joormann, J., \& Johnson, S. L. (2008). Responses to positive affect: A selfreport measure of rumination and dampening. Cognitive Therapy and Research, 32(4), 507-525. doi:10.1007/s10608-006-9083-0

Gentzler, A. L., Morey, J. N., Palmer, C. A., \& Yi, C. Y. (2012). Young Adolescents’ Responses to Positive Events: Associations With Positive Affect and Adjustment. The Journal of Early Adolescence, 33(5), 663-683. doi:10.1177/0272431612462629

Gentzler, A. L. \& Palmer, C. A. (2014). Positive Events and Responses Survey. Unpublished Measure.

Gross, J. J. (1998a). Antecedent- and response-focused emotion regulation: Divergent 
consequences for experience, expression, and physiology. Journal of Personality and Social Psychology, 74(1), 224-237. doi:10.1037/0022-3514.74.1.224

Gross, J. J. (1998b). The emerging field of emotion regulation: An integrative review. Review of General Psychology, 2(3), 271-299. doi:10.1037/1089-2680.2.3.271

Gross, J. J. \& John, O. P. (2003). Individual differences in two emotion regulation processes: Implications for affect, relationships, and well-being. Journal of Personality and Social Psychology, 85(2), 348-362. doi:10.1037/0022-3514.85.2.348

Gross, J. J. \& Munoz, R. F. (1995). Emotion regulation and mental health. Clinical Psychology, 2(2), 151-164. doi:10.1177/0192513X12437708

Gullone, E. \& Taffe, J. (2012). The Emotion Regulation Questionnaire for Children and Adolescents (ERQ-CA): A psychometric evaluation. Psychological Assessment, 24(2), 409-417. doi:10.1037/a0025777

Heiy, J. E. \& Cheavens, J. S. (2014). Back to Basics : A Naturalistic Assessment of the Experience and Regulation of Emotion. Emotion, 14(5), 878-891. doi:10.1037/a0037231

Larson, R. W., Moneta, G., Richards, M. H., \& Wilson, S. (2002). Continuity, Stability, and Change in Daily Emotional Experience across Adolescence. Child Development, 73(4), 1151-1165. doi:10.1111/1467-8624.00464

Livingstone, K. M. \& Srivastava, S. (2012). Up-regulating positive emotions in everyday life: Strategies, individual differences, and associations with positive emotion and well-being. Journal of Research in Personality, 46(5), 504-516. doi:10.1016/j.jrp.2012.05.009

Mayer, J. D., Roberts, R. D., \& Barsade, S. G. (2008). Human Abilities: Emotional Intelligence. Annu. Rev. Psychol, 59, 507-536. doi:10.1146/annurev.psych.59.103006.093646 
Quoidbach, J., Mikolajczak, M., \& Gross, J. J. (2015). Positive Interventions: An Emotion Regulation Perspective. Psychological Bulletin. Advance online publication. http://dx.doi.org/10.1037/a0038648

Riediger, M., Schmiedek, F., Wagner, G. G., \& Lindenberger, U. (2009). Seeking Pleasure and Seeking Pain. Psychological Science, 20(12), 1-7. doi:10.1111/j.14679280.2009.02473.x

Sheppes, G. \& Gross, J. J. (2012). Emotion Regulation Effectiveness: What Works When. In I. Weiner, H. A. Tennen, \& J. M. Suls (Eds.), Handbook of Psychology, Personality, and Social Psychology (2nd ed., pp. 391-403). Somerset, NJ: John Wiley \& Sons.

Şimşek, Ö. F. \& Çerçi, M. (2013). Relationship of the Gap Between Experience and Language With Mental Health in Adolescence: The Importance of Emotion Regulation. The Journal of Psychology, 147(3), 293-309.

Tamir, M., John, O. P., Srivastava, S., \& Gross, J. J. (2007). Implicit theories of emotion: Affective and social outcomes across a major life transition. Journal of Personality and Social Psychology, 92(4), 731-744. doi:10.1037/0022-3514.92.4.731

Waters, S. F. \& Thompson, R. A. (2014). Children's perceptions of the effectiveness of strategies for regulating anger and sadness. International Journal of Behavioral Development, 38(2), 174-181. doi:10.1177/0165025413515410

Webb, T. L., Miles, E., \& Sheeran, P. (2012). Dealing with feeling: A meta-analysis of the effectiveness of strategies derived from the process model of emotion regulation. Psychological Bulletin, 138(4), 775-808. doi:10.1037/a0027600

Zimmermann, G. (2010). Risk perception, emotion regulation, and impulsivity as predictors of risk behaviours among adolescents in Switzerland. Journal of Youth Studies, 13(1), 83- 
99. doi:10.1080/13676260903173488 
Table 1. Descriptive Statistics and Bivariate Correlations $(N=137-139)$

$\begin{array}{lllllllll}\text { Mean (SD) } & 1 & 2 & 3 & 4 & 5 & 6 & 7 & 8\end{array}$

1. Use of Maladaptive ER with NA $3.68(1.04) \quad---$

2. Perceived Effectiveness of Maladaptive ER with $2.68(.62) \quad .33^{* * *} \quad---$ NA

3. Use of Adaptive ER with NA

$4.54(.95) \quad-.06 \quad .02 \quad---$

4. Perceived Effectiveness of Adaptive ER with NA

$3.71(.58) \quad-.11 \quad-.09 \quad .54^{* * *} \quad---$

5. Use of Maladaptive ER with PA

$2.33(.66) \quad .47^{* * *} \quad .23^{* *} \quad-.19^{*} \quad-.13 \quad---$

6. Perceived Effectiveness of Maladaptive ER with $2.45(.58)$ $.31^{* * *} \quad .64^{* * *}$ $.01 \quad-.11 \quad .44^{* * *} \quad---$ PA

7. Use of Adaptive ER with PA $3.23(.63) \quad-.22^{* *} \quad-.15 \quad .51^{* * *} \quad .36^{* * *} \quad-.22^{* *} \quad-.18^{*} \quad---$

8. Perceived Effectiveness of Adaptive ER with PA $3.63(.53) \quad-.27^{* *} \quad-.17^{*} \quad .33^{* * *} \quad .46^{* * *} \quad-.20^{*} \quad-.19^{*} \quad .50^{* * *}$ Note. $\mathrm{NA}=$ negative affect. $\mathrm{PA}=$ positive affect. $\mathrm{ER}=$ emotion regulation. Raw scores are reported. Pairwise deletion. ${ }^{*} p<.05$. $^{* *} p<.01 .^{* * *} p<.001$. 
Table 2. Hierarchical Linear Regression Models

\begin{tabular}{|c|c|c|c|c|c|}
\hline 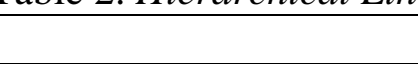 & & $\mathrm{R}^{2}$ & $\mathrm{df}$ & F Change & Beta \\
\hline \multicolumn{6}{|c|}{ Use of Maladaptive ER with NA } \\
\hline Step 1 & & .02 & 2,135 & 1.12 & \\
\hline \multirow{4}{*}{ Step 2} & Age & & & & .03 \\
\hline & Gender & & & & -.01 \\
\hline & & .11 & 1,134 & $14.57^{* * *}$ & \\
\hline & $\begin{array}{l}\text { Perceived Effectiveness of } \\
\text { Maladaptive ER with NA }\end{array}$ & & & & $.33^{* * *}$ \\
\hline \multicolumn{6}{|c|}{ Use of Adaptive ER with NA } \\
\hline Step 1 & & .00 & 2,133 & .27 & \\
\hline \multirow{4}{*}{ Step 2} & Age & & & & -.08 \\
\hline & Gender & & & & -.01 \\
\hline & & .36 & 1,132 & $74.23^{* * *}$ & \\
\hline & $\begin{array}{l}\text { Perceived Effectiveness of } \\
\text { Adaptive ER with NA }\end{array}$ & & & & $.60^{* * *}$ \\
\hline \multicolumn{6}{|c|}{ Use of Maladaptive ER with PA } \\
\hline Step 1 & & .00 & 2,135 & .18 & \\
\hline \multirow{4}{*}{ Step 2} & Age & & & & -.06 \\
\hline & Gender & & & & $.18^{*}$ \\
\hline & & .23 & 1,134 & $39.13^{* * *}$ & \\
\hline & $\begin{array}{l}\text { Perceived Effectiveness of } \\
\text { Maladaptive ER with PA }\end{array}$ & & & & $.52^{* * *}$ \\
\hline \multicolumn{6}{|c|}{ Use of Adaptive ER with PA } \\
\hline Step 1 & & .07 & 2,136 & $4.87^{* *}$ & \\
\hline \multirow{4}{*}{ Step 2} & Age & & & & $.24^{* *}$ \\
\hline & Gender & & & & $.18^{*}$ \\
\hline & & .33 & 1,135 & $52.65^{* * *}$ & \\
\hline & $\begin{array}{l}\text { Perceived Effectiveness of } \\
\text { Adaptive ER with PA }\end{array}$ & & & & $.51^{* * * *}$ \\
\hline
\end{tabular}

Note. $\mathrm{NA}=$ negative affect. $\mathrm{PA}=$ positive affect. $\mathrm{ER}=$ emotion regulation. Gender coded $0=$ male, $1=$ female. Beta's are from the final step of the regression. Listwise deletion. $* p<.05 . * * p$ $<.01 .^{* * * *} p<.001$. 
Appendices 


\section{Appendix A}

\section{Emotional Experience and Regulation among Adolescents}

During adolescence, maturation continues to take place in the physical, cognitive, and social domains. Specific to emotional development, middle and late adolescence have been considered the rock bottom of emotional experience in the life span (Larson, Moneta, Richards, \& Wilson, 2002). Numerous studies employing longitudinal and experience sampling methods suggest that middle and late adolescents experience higher rates of negative affect (NA) and lower rates of positive affect (PA) compared to earlier and later age periods (Arnett, 2002; Larson, Csikszantmihalyi, \& Graef, 1980; Larson et al., 2002; Larson \& Lampman-Petraitis, 1989; Larson \& Richards, 1994). For instance, adolescents in $9^{\text {th }}$ grade report experiencing time characterized as "very happy" $50 \%$ less often than their $5^{\text {th }}$ grade preadolescent counterparts (Arnett, 2002).

The downward trend of affect emphasized by Larson and colleagues (1980, 1989, 2002) is characterized by large variation in intensity of both positive and negative emotional states. A cross-sectional study examining late adolescents to older middle adults, revealed that age and affective intensity were negatively correlated $(r=-.26)$, suggesting that affective intensity decreases with age (Diener, Sandvik, \& Larsen, 1985). For example, adolescents experience extreme positive emotions five times as often and extreme negative emotions two times as often as their adult parents (Larson \& Richards, 1994).

The variability in emotional experience is coupled with instability in ER. A number of longitudinal and cross-sectional studies have revealed that young adolescents show the most instable ER with stability increasing as they grow older (Larson et al., 2002; Williams et al., 2006; Zimmermann \& Iwanski, 2014). Zimmermann and Iwanski (2014) show mean level shifts 
in adaptive ER with NA during adolescence. Specifically, adaptive strategies with NA show a Ushaped trajectory suggesting that adaptive strategies are used less during middle adolescence than before or after (Zimmermann \& Iwanski, 2014). Gullone, Hughes, King, and Tonge (2010), found that stability of ER strategy use may vary by specific strategy. For example, use of reappraisal was relatively stable in adolescents over a two-year period whereas, use of suppression significantly decreased over the same time frame (Gullone et al., 2010).

All of the above literature suggests that emotional difficulties may be more likely to occur during adolescence than at any other time in the life span (Arnett, 2002). Maladaptive ER is more prevalent as well as problematic during this time (Zimmer-Gembeck \& Skinner, 2011). Adolescence has also been considered a critical time during which maladaptive patterns may develop (Steinberg, 2005), suggesting this period of the life span is especially important to examine.

\section{Distinguishing between Adaptive and Maladaptive Emotion Regulation}

The bulk of ER research has focused on distinguishing between strategies that are putatively adaptive forms of regulating emotions and those that are not. Regulatory strategies are generally regarded as adaptive or maladaptive based on their association with positive or negative outcomes (e.g., psychopathology; Aldao, Nolen-Hoeksema, \& Schweizer, 2010; Aldao \& Nolen-Hoeksema, 2012; Augustine \& Hemenover, 2009; Feldman, Joormann, \& Johnson, 2008). This body of work contains relatively consistent findings regarding strategies' conception as adaptive or maladaptive forms of ER.

Maladaptive ER strategies have been linked to negative outcomes such as depression ( $r s$ ranging from .17 to .55) and anxiety ( $r$ r ranging from .29 to .42; Aldao et al., 2010; Feldman et al., 2008; Gentzler, Morey, Palmer, \& Yi, 2012; Lougheed \& Hollenstein, 2012). Strategies such 
as avoidance (i.e., avoiding thoughts or experiences of emotion), rumination (i.e., repeatedly focusing on the event or emotion), venting (i.e., overt expressions of emotion), and suppression (i.e., avoiding any display of emotion) have been linked to the aforementioned negative outcomes and considered maladaptive forms of ER with NA (Aldao \& Nolen-Hoeksema, 2012; Augustine \& Hemenover, 2009; Feldman et al., 2008; Gross \& John, 2003; Lougheed \& Hollenstein, 2012; Webb, Miles, \& Sheeran, 2012). Further, dampening and minimizing strategies that down-regulate or decrease PA have been considered maladaptive regulatory strategies with positive emotions (e.g., downplaying the significance; Feldman et al., 2008; Gentzler et al., 2012; Gentzler, Palmer, \& Ramsey, 2015). Dampening strategies have shown positive links to internalizing ( $r$ r ranging from .17 to .40$)$ and externalizing behaviors $(r=.42)$ and negative associations with well-being ( $r$ s ranging from -.26 to -.31; Gentzler et al., 2012, 2015).

Adaptive ER strategies exhibit negative associations with psychopathology ( $\mathrm{r} s$ ranging from .03 to -.33; Aldao et al., 2010; Aldao \& Nolen-Hoeksema, 2012; Gross \& John, 2003; Lougheed \& Hollenstein, 2012) and positive relations to outcomes such as psychological wellbeing ( rs ranging from .18 to .41; Gentzler et al., 2012, 2015; Gross \& John, 2003; Quoidbach, Berry, Hansenne, \& Mikolajczak, 2010). Strategies that are considered adaptive with NA include problem solving (i.e., thinking about how to handle the event), distraction (i.e., thinking about or doing something else), sharing (i.e., telling someone about the problem or feelings), and reappraisal (i.e., construing the situation in a way that changes its emotional impact; Aldao et al., 2010; Augustine \& Hemenover, 2009; Webb et al., 2012). With PA, savoring strategies that upregulate or increase positive emotions are considered to be adaptive forms of ER (e.g., absorbing the moment, sharing positive events; Bryant, 2003; Gentzler et al., 2012; Langston, 1994). 
Savoring strategies have shown positive associations with well-being ( $r s$ ranging from .18 to .37) and negative links to psychopathology (e.g., depression; rs ranging from -.12 to -.34; Bryant, 2003; Gentzler et al., 2015).

\section{Direct Effectiveness of Emotion Regulation Strategies}

The direct effectiveness of ER strategies (i.e., how successful a strategy is at decreasing, increasing, or maintaining emotional intensity; Sheppes \& Gross, 2012) with NA has been explored extensively in previous research (see Augustine \& Hemenover, 2009 and Webb et al., 2012 for reviews). Various experimental studies suggest that certain ER strategies are more effective at regulating negative emotions than others. Specifically, maladaptive strategies (e.g., expressive suppression) are not effective at decreasing the experience of NA (Gross, 1998a). While suppression does decrease outward facial expressions of negative emotions, it has shown to increase physiological responding (e.g., sympathetic activation; Gross \& John, 2003; Gross, 1998), suggesting that it is not an effective ER strategy. Conversely, adaptive strategies (e.g., reappraisal, problem-solving) are effective at decreasing the overall experience of NA (Goldin, McRae, Ramel, \& Gross, 2008; Gross, 1998a; Szasz, Szentagotai, \& Hofmann, 2011; Tan et al., 2012). For example, individuals who were instructed to use reappraisal to regulate disgust while watching a film clip not only reported a decreased subjective experience of disgust, but were similar to the control group (instructed to simply watch the film) in terms of sympathetic activation compared to individuals instructed to use suppression (Gross, 1998a).

The direct effectiveness of ER strategies with PA has been explored far less often. Recently, Quoidbach, Mikolajczak, and Gross (2015), compiled a review of studies focusing on positive ER interventions and their effectiveness by applying the Process Model of Emotion Regulation (Gross, 1998b). Strong evidence supports the effectiveness of attentional deployment 
(e.g., savoring the moment), cognitive change (e.g., think about how lucky you are), and response modulation (e.g., expressing PA; Quoidbach et al., 2015). However, more experimental work is needed on ER of positive emotions.

\section{Use of Adaptive and Maladaptive Emotion Regulation Strategies}

Much of the research on ER has focused on adaptive and maladaptive ER strategy's links to positive and negative outcomes (e.g., well-being; psychopathology; Aldao et al., 2010; Gentzler, Ramsey, Yi, Palmer, \& Morey, 2013). Less research has focused on predicting the use of these particular strategies. When research has examined individual differences, personality traits and attachment styles are commonly examined (see John \& Gross, 2007). Exploring individual differences in other constructs and their association with ER strategy use could be especially important for informing preventative and intervention approaches. Both distress tolerance (DT) and impulsivity have shown links to behavioral problems and psychopathology in previous research (Cooper, Wood, Orcutt, \& Albino, 2003; d'Acremont \& Van der Linden, 2007; Leyro, Zvolensky, \& Bernstein, 2010). Consequently, if individual differences that facilitate the development and use of maladaptive ER can be detected during adolescence then interventions and preventative approaches can be implemented in the hopes that the adolescent will develop adaptive ER abilities for adulthood.

Distress tolerance. The current literature has most commonly defined DT in two ways: the perceived capacity to withstand negative emotional and/or other aversive states (Simons \& Gaher, 2005), or the behavioral act of withstanding distressing internal states elicited by a stressor (Leyro et al., 2010; Zvolensky, Leyro, Bernstein, \& Vujanovic, 2010). However, debate on the theoretical conception, definition, and measurement of DT continues. In the present study, 
DT will most closely resemble the former definition (Simons \& Gaher, 2005), with a focus on individuals' tolerance of negative emotional states.

DT has generally been studied in relation to the development and maintenance of psychopathology with low DT (i.e., low capacity to withstand negative emotional states) being considered a transdiagnostic marker for multiple disorders (e.g., alcohol use, substance use, mood and personality disorders; Ameral, Palm Reed, Cameron, \& Armstrong, 2014; Ehrlich, Cassidy, Gorka, Lejuez, \& Daughters, 2013; see Leyro et al., 2010 for a review). Additionally, low DT has been considered a lower order component of emotion dysregulation (i.e., difficulty in emotional functioning, acceptance, and regulation of affective states; Gratz \& Roemer, 2004; Hawkins, Macatee, Guthrie, \& Cougle, 2013; Zvolensky et al., 2010). Specifically, low DT is theorized to be linked to maladaptive ER including strategies such as experiential avoidance, emotional suppression, and avoidant/disengagement coping (Zvolensky et al., 2010). Individuals who exhibit low DT may be more sensitive to the experience of distress and be more likely to use maladaptive regulatory strategies in response to stressful situations (Bardeen, Fergus, \& Orcutt, 2013; Hawkins et al., 2013; Leyro et al., 2010). In contrast, individuals with high DT (i.e., high capacity to withstand negative emotional states) are theorized to be more likely to use adaptive strategies to regulate negative emotions (Bardeen et al., 2013).

The association between DT and ER has been theorized to exist for over a decade. However, few researchers have examined this association empirically. Previous research that has explored this link has often utilized behavioral measures of DT in comparison to self-report (e.g., Bardeen, Tull, Dixon-Gordon, Stevens, \& Gratz, 2014). Moreover, the most common measure of ER that has been used in studies of DT is the Limited Access to Emotion Regulation Strategies scale of Gratz and Roemer's (2004) Difficulties in Emotion Regulation Scale (DERS; e.g., 
Bardeen et al., 2014; McHugh, Reynolds, Leyro, \& Otto, 2013). This particular scale assesses individual's beliefs that once someone is upset, there is not much that can be done to regulate emotions effectively (Gratz \& Roemer, 2004). McHugh and colleagues (2013) have found that low DT and limited access to effective ER strategies were uniquely and additively associated with higher levels of experiential avoidance in both clinical and non-clinical samples. In another study, results suggested that limited access to effective ER strategies was related to lower DT, but only in individuals who were also low on attentional control. While the Limited Access to Emotion Regulation Strategies scale has been commonly used, it does not directly assess use of specific ER strategies. The scale also only assesses access to ER strategies for negative emotions (i.e., upset). Since this scale is the only measure of ER used in previous studies with DT to our knowledge, the findings in regard to the association between ER and DT are limited.

While many researchers use behavioral tasks (i.e., frustrating or distressing tasks) to measure DT (Ameral et al., 2014; Bardeen et al., 2014; Daughters, Gorka, Magidson, MacPherson, \& Seitz-Brown, 2013; Daughters, Gorka, Rutherford, \& Mayes, 2014; Ehrlich et al., 2013; Ellis, Vanderlind, \& Beevers, 2013), other researchers believe that these tasks have been developed without reference to a conceptual model or theory (Zvolensky et al., 2010). Behavioral tasks are vulnerable to ceiling effects with as much as $22 \%$ of the sample reaching the end of the task without quitting (Ameral et al., 2014; Ehrlich et al., 2013). Research has also shown that approximately $40 \%$ of participants quit behavioral tasks assessing DT for reasons other than to escape discomfort (e.g., quitting once a certain goal was reached; Ameral et al., 2014; Zvolensky et al., 2010). This suggests that an accurate measurement of DT cannot be obtained for many participants when behavioral measures are used (Zvolensky et al., 2010). Although self-report measures are not without flaw, such instruments have been shown to 
measure habitual and dispositional tendencies (Aldao et al., 2010) rather than a distinct instance of behavior (Ameral et al., 2014). Self-report measures also give researchers the ability to examine constructs that cannot be measured objectively (Barrett, 2006). For these reasons, a selfreport measure of DT was used in the present study.

The majority of the research on DT has been conducted most often in relation to psychopathology with adults (see Leyro et al., 2010 for a review). Research with adolescents and non-clinical populations is more limited. Adolescents who find negative emotions especially aversive may be more likely to try anything to decrease distress even if the behavior is not adaptive. As previously mentioned, adolescence has also been considered a period of high NA and therefore may be an important time to investigate the role of DT on ER strategy use.

Impulsivity. Impulsivity is "the predisposition toward rapid, unplanned reactions to internal or external stimuli without regard of the negative consequences of these reactions" (Fossati, Gratz, Maffei, \& Borroni, 2013, p. 321). Impulsivity is proposed to stem from deficits in self-regulation of affect, motivation, and arousal (Cooper et al., 2003). Individual levels of impulsivity have shown to be a relatively stable dimension of socioemotional adjustment across childhood and adolescence (Eisenberg et al., 2005; Farrell \& Sullivan, 2000; Fossati et al., 2013; Weinberger \& Schwartz, 1990).

Childhood and adolescence are central age periods for the study of impulsivity as children learn to control their impulses through the development of executive functioning abilities (Barkley, 1997; Cooper et al., 2003). Research on impulsivity in adolescence generally explores associations with engagement in risky behaviors, such as substance use (Farrell \& Sullivan, 2000; Sher \& Trull, 1994; Whiteside \& Lynam, 2001). However, more recent research on impulsivity has examined its relation to emotions and ER (Boyer, 2006; Cooper et al., 2003; 
Cyders \& Smith, 2007; d'Acremont \& Van der Linden, 2007; Mitchell, Robertson, Anastopolous, Nelson-Gray, \& Kollins, 2012; Weitzman, McHugh, \& Otto, 2011).

Some researchers propose that impulsivity is a by-product of emotion dysregulation (i.e., insufficient ER precedes or causes impulsivity; Boyer, 2006; Mitchell et al., 2012; Weitzman et al., 2011), whereas other researchers suggest that instead impulsivity actually precedes the use of maladaptive regulatory strategies (Anestis, Selby, Fink, \& Joiner, 2007; d'Acremont \& Van der Linden, 2007). In one correlational study, d'Acremont and Van der Linden (2007) found that impulsive adolescents had more difficulty regulating negative emotions than adolescents who had greater impulse control. Further, impulsive traits were associated with the use of more maladaptive and less adaptive ER strategies (d'Acremont \& Van der Linden, 2007). These findings have also been replicated in relation to problem behaviors in adolescence. Specifically, maladaptive forms of ER (i.e., avoidance) were more strongly related to problem behavior in adolescents who exhibited high impulsivity compared to adolescents with low impulsivity (Cooper et al., 2003). Overall, this body of work suggests that impulsivity may increase adolescents' risk of using maladaptive ER strategies with NA, though its association with ER with positive emotions is less clear.

Considering both impulsivity and distress tolerance. It may be important to consider how these risk factors for maladaptive ER could interact in relation to each other. Impulsivity has been linked to distress in a number of studies (Anestis et al., 2007; Farrell \& Sullivan, 2000; Weinberger \& Schwartz, 1990; Weitzman et al., 2011). Weinberger and Schwartz (1990) created a six group typology for low, moderate, and high levels of self-restraint (i.e., the higher order component of impulse control) and low and high levels of distress. Individuals with high levels 
of distress and low levels of self-restraint were hypothesized to have trouble managing their emotions (Weinberger \& Schwartz, 1990; Weinberger, 1996).

Weitzman and colleagues (2011) examined the relationship between impulsivity, distress intolerance, and access to ER strategies (as measured by the DERS; Gratz \& Roemer, 2004) in two large adult samples. Results revealed that low tolerance to distress and limited access to ER strategies additively predicted impulsivity (Weitzman et al., 2011), suggesting that distress intolerance and inability to access effective ER strategies were both associated with the likelihood of acting impulsively. Conversely, a study by Anestis and colleagues (2007) took a different directional approach to predict eating disorder symptoms in a sample of undergraduate college students. Findings indicated that DT predicted bulimic symptoms above and beyond a number of covariates (e.g., gender, depression, anxiety; Anestis et al., 2007). Furthermore, moderation analyses showed a two-way interaction of DT and impulsivity predicting bulimic symptoms. Specifically, individuals with a low tolerance to distress and high level of impulsivity reported the highest number bulimic symptoms (Anestis et al., 2007). Thus, examining how effects of one risk (e.g., low DT) may be exacerbated when adolescents also have another risk (e.g., high impulsivity) could offer additional insight into who is more likely to use maladaptive ER strategies.

\section{Research Questions and Hypotheses}

\section{Research Question 2}

How does adolescents' level of DT relate to their use of ER strategies?

Hypothesis 2a. Adolescents who report low tolerance to emotional distress will report a greater likelihood of using maladaptive ER strategies with NA. 
Hypothesis 2b. Adolescents who report high tolerance to emotional distress will report a greater likelihood of using adaptive ER strategies with NA.

Hypothesis 2c (exploratory). The association between adolescents' DT and their use of adaptive and maladaptive ER strategies with PA has not been explored by previous research. The association will be examined on an exploratory basis without specific hypotheses.

\section{Research Question 3}

How does adolescents' level of impulsivity relate to their use of ER strategies?

Hypothesis 3a. Adolescents who report high impulsivity will report a greater likelihood of using maladaptive ER strategies with NA.

Hypothesis 3b. Adolescents who report low impulsivity will report a greater likelihood of using adaptive ER strategies with NA.

Hypothesis 3c (exploratory). Adolescent impulsivity has not been explored in relation to their use of adaptive and maladaptive ER strategies with PA. To further research on impulsivity and ER, this association will be examined on an exploratory basis without specific hypotheses.

\section{Research Question 4 (exploratory)}

Does adolescents' impulsivity moderate the association between DT and ER strategy use?

Hypothesis 4a. The relationship between adolescents' DT and use of maladaptive ER with NA will be stronger for those with higher impulsivity compared to those with lower impulsivity.

\section{Method}

\section{Participants}


Participants were 143 adolescents recruited from high schools in the North Eastern U.S. as part of a larger study. Data were screened for patterned responding by insuring accuracy of two validity checks (e.g., "Please answer 2 for this item") and calculating individual participant standard deviations for each measure. Fourteen participants failed one validity check but were maintained in the sample because of a misunderstanding with the validity questions. None of the participants failed both validity checks. One participant was dropped from the sample because of a lack of variability in responding (SD of zero on multiple measures) suggesting patterned responding. Incomplete data on measures of interest also resulted in five participants being dropped from the sample.

The final sample of 137 adolescents ranged in age from 14 to 18 years old $(M=15.51$, $S D=.89 ; 60.3 \%$ male). The participants reflected the socio-demographic characteristics of the areas from which they were recruited. Specifically, $81.6 \%$ of the sample self-identified as White/Caucasian, 7.4\% as African American, 5.9\% as other or multiple ethnicities, $2.9 \%$ as Asian or Asian American, 1.5\% as Hispanic/Latin American, and .7\% as Pacific Islander or Native Hawaiian. See main document for parent-reported demographic information.

\section{Procedure}

See main document for procedure.

\section{Measures}

Use of emotion regulation strategies for negative affect. See main document. Use of emotion regulation strategies for positive affect. See main document.

Distress tolerance. The Distress Tolerance Scale (DTS; Simons \& Gaher, 2005) has been considered the gold standard in the assessment of an individual's perceived capacity to withstand distressing negative emotional states (Ameral et al., 2014; Lejuez, Banducci, \& Long, 
2013; Simons \& Gaher, 2005). The DTS is comprised of four scales: Tolerance (i.e., ability to tolerance emotional distress), Appraisal (i.e., subjective appraisal of distress), Absorption (i.e., attention that is absorbed by distress), and Regulation (i.e., efforts to regulate/relieve distress). However, only the full scale was used in the present study to consider the construct of DT in entirety rather than the separate subcomponents' relation to ER. Also, in the current study, a slightly adapted version of the DTS was used (Saulsman \& Nathan, 2012). Adolescents reported their perceived ability to tolerate distress to 15 items that were rated on a 5-point Likert-type scale $(1=$ Strongly agree to $5=$ Strongly disagree $)$. Higher scores on this scale indicate a high tolerance for emotional distress, whereas lower scores indicate a low tolerance. An example item on this scale is: "Feeling distressed or upset is unbearable to me." The DTS has demonstrated high internal consistency and discriminant validity in past research, (alphas between .82 and .91; Hawkins et al., 2013; Simons \& Gaher, 2005) as well as in the present study $(\alpha=.88)$.

Impulsivity. The Impulse Control subscale of the Self-Restraint scale on the Weinberger Adjustment Inventory (Weinberger \& Schwartz, 1990) has been used with individuals ranging from 10 to 65 years old. It was used in the current study to assess adolescent impulsivity. Adolescents reported on a 5-point Likert-type scale $(1=$ False, $2=$ Somewhat False, $3=$ Unsure, $4=$ Somewhat True, $5=$ True) to eight items that assess one's ability to control impulses. An example item from this scale is "I do things without giving them enough thought." Higher scores on this scale indicate higher levels of impulsivity. The Impulse Control subscale has exhibited adequate reliability in previous research $(\alpha=.82$; Vandell, Belsky, Burchinal, Steinberg, \& Vandergrift, 2010) and in the present study $(\alpha=.84)$.

\section{Results and Discussion}

\section{Preliminary Analysis}


To create the scales for each variable, participants were required to have $80 \%$ of the items completed. If $80 \%$ of the items were not completed, participants did not receive a score for that particular scale. Outliers were determined by a Mahalanobis distance greater than 18.47 as determined by chi-square with four degrees of freedom and p-value less than .001 . There were no outliers in the present sample. The main study variables' means, standard deviations, and bivariate correlations are presented in Table A1. Age was significantly correlated with Adaptive ER with PA $(r=.22)$, suggesting that older adolescents up-regulate PA more than younger adolescents.

\section{Primary Analyses}

A series of hierarchical linear regression models were performed to examine the associations among Impulsivity, DT, and use of ER strategies. Although age was the only demographic variable correlated with any of the outcome variables in the present study, previous research has shown that adolescent use of ER strategies varies by both age and gender (e.g., Waters \& Thompson, 2014; Zimmermann \& Iwanski, 2014). Therefore, in step one of each analysis, age and gender were entered as covariates. Listwise deletion was utilized in all analyses.

Research Question 2: How does adolescents' level of DT relate to their use of ER strategies?

To test Hypothesis 2a, that adolescents' DT is associated with their use of maladaptive ER strategies with NA, a hierarchical linear regression was performed. The full model was significant, $F(1,133)=13.01, p<.001, R^{2}=.11$. Gender was a marginally associated with Maladaptive ER with NA $(\beta=-.16, p=.05)$, suggesting that males use more maladaptive strategies with NA than females. In line with hypotheses, low tolerance to distress was related to higher likelihood of using maladaptive strategies $(\beta=-.30, p<.001)$. 
It has been widely theorized that individuals with low DT may also use more maladaptive ER strategies, specifically with NA (Bardeen et al., 2013; Hawkins et al., 2013; Leyro et al., 2010). The present study provides evidence to support this theory. Although some research has shown that ER strategies were not differentially related to DT (e.g., Ellis et al., 2013), these studies employed task persistence and behavioral tasks, whereas the DTS (used in the present study) may relate more specifically to negative emotional tolerance (Cougle, Bernstein, Zvolensky, Vujanovic, \& MacAtee, 2013; Simons \& Gaher, 2005).

To test Hypothesis 2b, that adolescents who report high tolerance to emotional distress will also report a greater likelihood of using adaptive ER strategies with NA, a hierarchical linear regression was performed. The full model was non-significant, $F(1,132)=2.28, p=.13, R^{2}=$ .02. Neither age, nor gender were significant. Contrary to hypotheses, DT was not a significant predictor of adaptive ER strategy use with negative emotions.

Previous literature on DT has theorized that individuals with a high tolerance to distress may be using more adaptive forms of ER with negative emotions (Bardeen et al., 2013; Leyro et al., 2010). However, the current study's empirical examination of this theory suggests that DT is not a significant predictor in the use of adaptive ER strategies with NA.

Hypothesis 2c examined the relation between adolescent DT and ER with positive emotions which has not been explored by previous research. Conceptually, because DT is the capacity to withstand negative emotional states, an association was not expected between DT and ER with positive emotions, but research on positive emotions is novel and it is important to explore potential associations.

Separate hierarchical linear regressions were conducted to explore the association between DT and use of Maladaptive and Adaptive ER with PA. For Maladaptive ER with PA, 
the full model was significant, $F(1,133)=7.32, p=.01, R^{2}=.05$, suggesting that a low tolerance to distress is associated with a higher likelihood of using maladaptive strategies to regulate PA ( $\beta$ $=-.23, p=.01)$. Similarly, for Adaptive ER strategies with PA, the full model was significant, $F(1,133)=9.32, p=.01, R^{2}=.14$. Age $(\beta=.21, \mathrm{p}=.01)$ and $\mathrm{DT}(\beta=-.25, \mathrm{p}=.01)$ were significantly related to Adaptive ER with PA, while gender was marginally significant, $\beta=.15, p$ $=.07$. In general, older adolescents, female adolescents, and adolescents with a low tolerance to distress reported higher levels of adaptive ER strategies with PA.

Contrary to assumptions, DT was related to the use of both adaptive and maladaptive ER with PA. To our knowledge, this association has not been explored previously and therefore may constitute an interesting extension of existing research on the link between DT and ER. Specifically, adolescents with a low level of DT report using both adaptive and maladaptive strategies to regulate positive emotions. This may suggest that these adolescents do not know what to do with their positive emotions. For instance, adolescents may be weighing the costs and benefits of trying to use positive emotions to counter negative emotions (up-regulate PA), or avoid emotional states altogether (down-regulate PA). Previous research with college students shows that extreme valuing of happiness is related to both up-regulating and down-regulating of positive emotions (Gentzler et al., 2015). This may suggest that when individuals feel an extreme desire to be happy and potentially equating happiness with experiencing no negative emotions (McMahan et al., 2015), they may be willing to try anything to reach this goal, including strategies that have been considered putatively maladaptive forms of ER.

Research Question 3: How does adolescents' level of impulsivity relate to their use of ER strategies? 
To examine Hypothesis 3a, that adolescents who report high impulsivity will report a greater likelihood of using maladaptive ER strategies with NA, a hierarchical linear regression was performed. The full model was significant, $F(1,133)=4.62, p=.03, R^{2}=.05$. Specifically, adolescents with higher levels of impulsivity reported using greater Maladaptive ER with NA ( $\beta$ $=.18, p=.03)$.

Consistent with previous research with adolescents (d'Acremont \& Van der Linden, 2007), the present study found that impulsivity was linked to the use of greater maladaptive ER strategies with negative emotions. Dysregulation of emotions had been linked to impulsivity in previous studies (Boyer, 2006; Cooper et al., 2003; Mitchell et al., 2012). For instance, Cooper and colleagues (2003) have shown that maladaptive ER and poor impulse control are related to problem behaviors and vulnerabilities during adolescence. In a review paper, Boyer (2006) suggested that individuals who lack effective ER skills are more likely to engage in hasty decision making. However, many of these studies suggest that impulsivity is a by-product of emotion dysregulation. Future research should aim to disentangle the direction of this association. Specifically, does impulsivity predict maladaptive ER over time, does maladaptive ER predict impulsivity over time, or is this a bidirectional association? Further exploring this link could be beneficial for interventions with adolescents that focus on impulse control and ER.

To explore Hypothesis 3b, that adolescents who report low impulsivity will report a greater likelihood of using adaptive ER strategies with NA, a hierarchical linear regression was performed. The full model was significant, $F(1,132)=5.10, p=.03, R^{2}=.04$. In line with hypotheses, lower impulsivity was associated with a greater likelihood of using Adaptive ER with NA $(\beta=-.19, p=.03)$. 
Although the majority of research in adolescence focuses on examining the negative outcomes related to high levels of impulsivity, we found new evidence that adolescents reporting lower levels of impulsivity also report using more adaptive ER strategies with NA. This connection can likely be drawn from the fact that individuals with more developed selfregulatory abilities are better equipped to regulate across all domains, including emotions (Steinberg, 2005).

Hypothesis 3c explored a link that previous research has not thoroughly examined: the association between impulsivity and ER with positive emotions. Because ER with positive emotions is also consequential for adolescents' well-being (Bijttebier, Raes, Vasey, \& Feldman, 2012; Gentzler et al., 2012), it is important to explore how adolescent impulsivity may be related to their use of Adaptive and Maladaptive ER strategies with PA. Separate hierarchical linear regressions were conducted to explore the association between impulsivity and use of Maladaptive and Adaptive ER with PA, respectively. For Maladaptive ER with PA, the model was non-significant, $F(1,133)=2.88, p=.09, R^{2}=.02$. For Adaptive ER with PA, step one of this model was significant, $F(2,134)=5.69, p=.01, R^{2}=.08$, with age $(\beta=.24, p=.01)$ and gender $(\beta=.17, p=.04)$ both being associated with use of adaptive ER strategies with positive emotions. Specifically, older adolescents and female adolescents reported using more adaptive strategies with PA than younger and male adolescents. However in step two, impulsivity did not account for a significant amount of additional variance in Adaptive ER with PA, $F(1,133)=$ $1.44, p=.23, R^{2}=.09$.

In the present study, impulsivity was not a significant predictor of either adaptive or maladaptive ER with positive emotions. However, previous literature has shown that impulsivity and substance use and risk-taking are related, especially during adolescence (e.g., Sher \& Trull, 
1994). Both substance use and risk-taking, although not assessed in the current study, could be considered maladaptive ER strategies used to up-regulate or maintain PA (e.g., pleasure, excitement) that are part of antecedent ER (i.e., selecting situations to feel certain ways; Gross, 1998b). Thus, future research is necessary to further explore the associations between impulsivity and other forms of ER with positive emotions.

Research Question 4 (exploratory): Does adolescents' impulsivity moderate the association between DT and ER strategy use?

To test Hypothesis 4a, that the association between adolescents' DT and use of Maladaptive ER with NA will be stronger for those with higher impulsivity compared to those with lower impulsivity, a hierarchical linear regression was conducted. Age and gender were entered in step one, centered terms for DT and Impulsivity in step two, and the interaction term (DTxImpulsivity) in step three. Maladaptive ER with NA was the outcome variable. The interaction term did not significantly add to the model. Exploratory analyses were performed to examine possible moderation with other forms of ER (i.e., Adaptive ER with NA, Maladaptive ER with PA, Adaptive ER with PA). In each model, the interaction term did not significantly add to the model (see Table A2, Step 3 of each model).

Although previous literature has theorized that impulsivity and DT together may exacerbate the direct effects each has on ER (e.g., Simons \& Gaher, 2005), the present study does not provide evidence for this theory. In other domains of research (e.g., eating disorders; Anestis et al., 2007), a dual interaction has been observed suggesting that levels of DT and impulsivity are predictive of some dysregulated behaviors (e.g., bulimic symptoms), but this was not the case in the current study. One consideration is that the combination of high levels of impulsivity and low levels of DT are rare in a non-clinical sample of adolescents. It is also 
possible that this interactive effect may only be true for certain ER strategies and not maladaptive strategies overall. Future research is needed to explore individual strategies and compare clinical and non-clinical samples of adolescents.

Interestingly, when examining the moderation models, differences in the main effects of DT and impulsivity were observed when both constructs were included in the model in comparison to the regressions in which they were separate (see Table 2, Step 2). Specifically, when DT is included in the model impulsivity is no longer significantly associated with Maladaptive ER with NA. Further, DT becomes significantly related to Adaptive ER with NA when impulsivity is included in the model. Lastly, impulsivity becomes a marginally associated with Adaptive ER with PA when DT is included in the model.

\section{Structural Equation Model}

To complement the regression models and to account for covariance among the dependent variables, a structural equation model was conducted using SPSS Amos 21 with maximum likelihood estimation. DT and impulsivity were modeled as predictors of each ER strategy type (Maladaptive ER with NA, Adaptive ER with NA, Maladaptive ER with PA, Adaptive ER with PA). Age and gender were included as covariates. The initial model fit was poor, $\chi^{2}(15, \mathrm{~N}=136)=106.68, p<.001$, Comparative Fit Index $(\mathrm{CFI})=.31, \chi^{2} / d f$ ratio $=7.11$, root mean square error of approximation $(\mathrm{RMSEA})=.21[90 \% \mathrm{CI}=.18, .25]$ (see Figure A1). To improve model fit, non-significant parameters were removed including age and gender as covariates, $\chi^{2}(9, \mathrm{~N}=136)=95.28, p<.001, \mathrm{CFI}=.30, \chi^{2} / d f$ ratio $=10.59, \mathrm{RMSEA}=.27[90 \%$ $\mathrm{CI}=.22, .32]$. In addition, modification indices suggested allowing DT and Impulsivity to covary, $\chi^{2}(8, \mathrm{~N}=136)=89.84, p<.001, \mathrm{CFI}=.33, \chi^{2} / d f$ ratio $=11.23, \mathrm{RMSEA}=.28[90 \% \mathrm{CI}=$ $.23, .33]$, which makes conceptual sense based on the fact that the two constructs are 
significantly correlated $(r=.20)$. Modification indices also suggested covarying the error terms for ER strategies to account for unique measurement variance associated with each type of ER. The resulting model provided a good fit to the data, $\chi^{2}(3, \mathrm{~N}=136)=4.33, p=.23, \mathrm{CFI}=.99$, $\chi^{2} / d f$ ratio $=1.44, \mathrm{RMSEA}=.06[90 \% \mathrm{CI}=.00, .17]($ see Figure A2), and indicated that low tolerance to distress was significantly associated with greater use of all four types of ER: Maladaptive ER with NA $(\beta=-.28, p<.001)$, Adaptive ER with NA $(\beta=-.18, p=.04)$, Maladaptive ER with PA $(\beta=-.21, p=.01)$, and Adaptive ER with PA $(\beta=-.32, p<.001)$, respectively. In addition, Impulsivity was also negatively related to use of Adaptive ER with NA $(\beta=-.22, p=.01)$, suggesting that adolescents with a high level of impulsivity use less adaptive ER strategies with negative emotions. These findings are identical to the results of the regressions reported for research question four in which both DT and impulsivity were included in the model.

\section{Full Discussion}

The present study's results suggest that DT's association with ER is unclear. Specifically, adolescents with a low tolerance to distress seem to be regulating emotions in any and every way possible. We suggest two ways these findings could be interpreted. First, adolescents with a low DT may be a very heterogeneous group and perhaps the present study is observing the great variability within this group of people. Another potential explanation is that individuals with a low DT may not know how to regulate their emotions. DT has been theorized to be linked to emotion dysregulation by previous research (Hawkins et al., 2013; Simons \& Gaher, 2005; Zvolensky et al., 2010). Moreover, Simons and Gaher (2005) suggest that individuals with a low DT may use rapid means of alleviating negative emotions. These adolescents may be overwhelmed by negative emotional experiences and are grasping at any strategy to try and 
regulate their negative emotions. This distress and dysregulation of negative emotions may spill over into the regulation of positive emotions in that they try any and every way to regulate positive emotions as well. Specifically, some adolescents with low DT may be using positive emotions as a buffer against negative emotions by trying to savor or up-regulate positive experiences. Conversely, other adolescents may be dampening, or down-regulating, their positive emotions as a broad coping mechanism to avoid or suppress any emotional experience at all. Impulsivity's relation to ER strategy use seems to be dependent upon DT in some cases and a strong main effect of its own in other cases. When impulsivity is the sole predictor (beyond covariates) in regression analyses, it is significantly associated with both maladaptive and adaptive ER with NA in expected ways. However, when DT is added to the model, impulsivity is no longer significantly related to maladaptive ER with NA. It is likely that DT and impulsivity share variance, as the variables are significantly correlated with one another $(r=-.20, p=.02)$. Although it is often assumed that since high levels of impulsivity are generally linked to maladaptive ER with NA (although this was not the case in the present study when DT was included in the model), it is inappropriate to assume that low levels of impulsivity are therefore associated with adaptive ER with NA. The association between impulsivity and adaptive ER with NA was explicitly explored in the present study to verify this relation does exist. Contrary to other outcomes currently under investigation, impulsivity had the strongest association with Adaptive ER with NA (i.e., low impulsivity is related to higher levels of Adaptive ER with NA). Impulsivity is generally not examined in relation to positive emotions. When impulsivity is the sole predictor (beyond covariates), it is unrelated to ER with PA. Interestingly, when DT is included in the model, low levels of impulsivity are marginally related to higher levels of Adaptive ER with PA. To our knowledge, similar associations have not been previously explored 
or reported by previous literature. The study of positive emotions is a novel field and may not have examined this association previously.

\section{Limitations and Future Directions}

Although the current study presented numerous unique findings as well as extending previous research, there are a few limitations. The present study's sample was predominately upper-class and White. For these findings to be generalizable, replication with a more ethnically and socioeconomically diverse sample will be needed. The present study was also crosssectional. Longitudinal research is needed to examine the development of these constructs over time as well as determine the direction of effects. Something that should also be considered is the possibility that strategies deemed maladaptive in the literature may work for the adolescents who endorse them (e.g., some adolescents may have become very skilled at avoidance such that is effective for them). Moreover, our definition of "effective" ER (i.e., down-regulate NA, upregulate PA) may not be true in all cases, especially adolescence. Previous research has shown that some adolescents pursue contra-hedonic states (Riediger, Schmiedek, Wagner, \& Lindenberger, 2009). In this instance, adolescents want to feel bad and maladaptive strategies would be effective in achieving that emotional goal.

Future research should consider the individual's goal and context when assigning ER strategies to categories such as adaptive and maladaptive (Aldao, 2013; Riediger et al., 2009). It also may be of interest to examine individual strategies instead of aggregating at the adaptive/maladaptive level as individual ER strategies may be differentially associated with DT or impulsivity. Examining the difference between individual emotions rather than generally exploring positive and negative emotions may also bring to light specific differences in the associations between DT, impulsivity, and ER. 
Although preliminary, the current study has identified and explored gaps in existing literature by examining DT and impulsivity with adaptive ER as well as ER with positive emotions. By further extending previous research and addressing new areas, the present study constitutes a stepping stone in the examination of predictors of adolescent ER strategy use. 


\section{References}

Aldao, A. (2013). The future of emotion regulation research: Capturing context. Perspectives on Psychological Science, 8(2), 155-172. doi:10.1177/1745691612459518

Aldao, A. \& Nolen-Hoeksema, S. (2012). When are adaptive strategies most predictive of psychopathology? Journal of Abnormal Psychology, 121(1), 276-281. doi:10.1037/a0023598

Aldao, A., Nolen-Hoeksema, S., \& Schweizer, S. (2010). Emotion-regulation strategies across psychopathology: A meta-analytic review. Clinical Psychology Review, 30(2), 217-37. doi:10.1016/j.cpr.2009.11.004

Ameral, V., Palm Reed, K. M., Cameron, A., \& Armstrong, J. L. (2014). What Are Measures of Distress Tolerance Really Capturing? A Mixed Methods Analysis. Psychology of Consciousness: Theory, Research, and Practice. Advance Online Publication., 1(4), 13.

Anestis, M. D., Selby, E. A., Fink, E. L., \& Joiner, T. E. (2007). The Multifaceted Role of Distress Tolerance in Dysregulated Eating Behaviors. The International Journal of Eating Disorders, 40, 718-726. doi:10.1002/eat

Arnett, J. J. (2002). Adolescent Storm and Stress, Reconsidered. In J. J. Arnett (Ed.), Readings on Adolescence and Emerging Adulthood (pp. 6-16). Upper Saddle River, NJ: Pearson Education, Inc.

Augustine, A. A. \& Hemenover, S. H. (2009). On the relative effectiveness of affect regulation strategies: A meta-analysis. Cognition \& Emotion, 23(6), 1181-1220.

doi:10.1080/02699930802396556

Bardeen, J. R., Fergus, T. A., \& Orcutt, H. K. (2013). Testing a hierarchical model of distress tolerance. Journal of Psychopathology and Behavioral Assessment, 35(4), 495-505. doi:10.1007/s10862-013-9359-0

Bardeen, J. R., Tull, M. T., Dixon-Gordon, K. L., Stevens, E. N., \& Gratz, K. L. (2014). Attentional Control as a Moderator of the Relationship Between Difficulties Accessing Effective Emotion Regulation Strategies and Distress Tolerance. Journal of Psychopathology and Behavioral Assessment. doi:10.1007/s10862-014-9433-2

Barkley, R. A. (1997). Behavioral inhibition, sustained attention, and executive functions: Constructing a unifying theory of ADHD. Psychological Bulletin, 121(1), 65-94. doi:10.1037/0033-2909.121.1.65

Bijttebier, P., Raes, F., Vasey, M. W., \& Feldman, G. C. (2012). Responses to positive affect predict mood symptoms in children under conditions of stress: A prospective study. Journal of Abnormal Child Psychology, 40(3), 381-389. doi:10.1007/s10802-011-9579-2 
Boyer, T. W. (2006). The development of risk-taking: A multi-perspective review. Developmental Review, 26(3), 291-345. doi:10.1016/j.dr.2006.05.002

Bryant, F. (2003). Savoring Beliefs Inventory (SBI): A scale for measuring beliefs about savouring. Journal of Mental Health, 12(2), 175-196.

doi:10.1080/0963823031000103489

Cooper, M. L., Wood, P. K., Orcutt, H. K., \& Albino, A. (2003). Personality and the predisposition to engage in risky or problem behaviors during adolescence. Journal of Personality and Social Psychology, 84(2), 390-410. doi:10.1037/0022-3514.84.2.390

Cougle, J. R., Bernstein, A., Zvolensky, M. J., Vujanovic, A. A., \& MacAtee, R. J. (2013). Validation of self-report measures of emotional and physical distress tolerance. Journal of Psychopathology and Behavioral Assessment, 35(1), 76-84. doi:10.1007/s10862-0129317-2

Cyders, M. A., \& Smith, G. T. (2007). Mood-based rash action and its components: Positive and negative urgency. Personality and Individual Differences, 43(4), 839-850. doi:10.1016/j.paid.2007.02.008

d'Acremont, M. \& Van der Linden, M. (2007). How is impulsivity related to depression in adolescence? Evidence from a French validation of the cognitive emotion regulation questionnaire. Journal of Adolescence, 30(2), 271-282.

doi:10.1016/j.adolescence.2006.02.007

Daughters, S. B., Gorka, S. M., Magidson, J. F., MacPherson, L., \& Seitz-Brown, C. J. (2013). The role of gender and race in the relation between adolescent distress tolerance and externalizing andinternalizing psychopathology. Journal of Adolescence, 36(6), 10531065. doi:10.1016/j.adolescence.2013.08.008

Daughters, S. B., Gorka, S. M., Rutherford, H. J. V, \& Mayes, L. C. (2014). Maternal and adolescent distress tolerance: The moderating role of gender. Emotion (Washington, D.C.), 14(2), 416-24. doi:10.1037/a0034991

Diener, E., Sandvik, E., \& Larsen, R. (1985). Age and sex effects for emotional intensity. Developmental Psychology, 21(3), 542-546. doi:10.1037/0012-1649.21.3.542

Ehrlich, K. B., Cassidy, J., Gorka, S. M., Lejuez, C. W., \& Daughters, S. B. (2013). Adolescent friendships in the context of dual risk: The roles of low adolescent distress tolerance and harsh parental response to adolescent distress. Emotion, 13(5), 843-51.

doi:10.1037/a0032587

Eisenberg, N., Sadovsky, A., Spinrad, T. L., Fabes, R. A., Losoya, S. H., Valiente, C., ... Shepard, S. A. (2005). The relations of problem behavior status to children's negative emotionality, effortful control, and impulsivity: Concurrent relations and prediction of change. Developmental Psychology, 41(1), 193-211. doi:10.1037/0012-1649.41.1.193 
Ellis, A. J., Vanderlind, W. M., \& Beevers, C. G. (2013). Enhanced anger reactivity and reduced distress tolerance in major depressive disorder. Cognitive Therapy and Research, 37(3), 498-509. doi:10.1007/s10608-012-9494-Z

Farrell, A. D. \& Sullivan, T. N. (2000). Structure of the Weinberger Adjustment Inventory SelfRestraint scale and its relation to problem behaviors in adolescence. Psychological Assessment, 12(4), 394-401. doi:10.1037/1040-3590.12.4.394

Feldman Barrett, L. (2006). Solving the emotion paradox: Categorization and the experience of emotion. Personality and Social Psychology Review: An Official Journal of the Society for Personality and Social Psychology, Inc, 10(1), 20-46. doi:10.1207/s15327957pspr1001_2

Feldman, G. C., Joormann, J., \& Johnson, S. L. (2008). Responses to positive affect: A selfreport measure of rumination and dampening. Cognitive Therapy and Research, 32(4), 507-525. doi:10.1007/s10608-006-9083-0

Fossati, A., Gratz, K. L., Maffei, C., \& Borroni, S. (2013). Emotion dysregultion and impulsivity additively predict borderline personality disorder features in Italian nonclinical adolescents. Personality and Mental Health, 7, 320-333. doi:10.1002/pmh

Gentzler, A. L., Morey, J. N., Palmer, C. A., \& Yi, C. Y. (2012). Young Adolescents' Responses to Positive Events: Associations With Positive Affect and Adjustment. The Journal of Early Adolescence, 33(5), 663-683. doi:10.1177/0272431612462629

Gentzler, A. L., Palmer, C. A., \& Ramsey, M. A. (2015). Savoring with Intent: Investigating Types of and Motives for Responses to Positive Events. Journal of Happiness Studies. doi:10.1007/s10902-015-9625-9

Gentzler, A. L., Ramsey, M. A., Yi, C. Y., Palmer, C. A., \& Morey, J. N. (2013). Young adolescents' emotional and regulatory responses to positive life events: Investigating temperament, attachment, and event characteristics. The Journal of Positive Psychology, 9(2), 108-121. doi:10.1080/17439760.2013.848374

Goldin, P. R., McRae, K., Ramel, W., \& Gross, J. J. (2008). The Neural Bases of Emotion Regulation: Reappraisal and Suppression of Negative Emotion. Biological Psychiatry, 63(6), 577-86. doi:10.1016/j.biopsych.2007.05.031

Gratz, K. L. \& Roemer, L. (2004). Multidimensional assessment of emotion regulation and dysregulation. Journal of Psychopathology and Behavioral Assessment, 26(1), 41-54. doi:10.1023/B:JOBA.0000007455.08539.94

Gross, J. J. (1998a). Antecedent- and response-focused emotion regulation: Divergent consequences for experience, expression, and physiology. Journal of Personality and Social Psychology, 74(1), 224-237. doi:10.1037/0022-3514.74.1.224 
Gross, J. J. (1998b). The emerging field of emotion regulation: An integrative review. Review of General Psychology, 2(3), 271-299. doi:10.1037/1089-2680.2.3.271

Gross, J. J., \& John, O. P. (2003). Individual differences in two emotion regulation processes: Implications for affect, relationships, and well-being. Journal of Personality and Social Psychology, 85(2), 348-362. doi:10.1037/0022-3514.85.2.348

Gullone, E., Hughes, E. K., King, N. J., \& Tonge, B. (2010). The normative development of emotion regulation strategy use in children and adolescents: A 2-year follow-up study. Journal of Child Psychology and Psychiatry and Allied Disciplines, 51(5), 567-574. doi:10.1111/j.1469-7610.2009.02183.x

Hawkins, K. A., Macatee, R. J., Guthrie, W., \& Cougle, J. R. (2013). Concurrent and prospective relations between distress tolerance, life stressors, and anger. Cognitive Therapy and Research, 37(3), 434-445. doi:10.1007/s10608-012-9487-y

John, O. J. \& Gross, J. J. (2007). Individual differences in emotion regulation. In J. J. Gross (Ed.), Handbook of Emotion Regulation (pp. 351-372). New York, NY: Guilford Press.

Langston, C. A. (1994). Capitalizing on and coping with daily-life events: Expressive responses to positive events. Journal of Personality and Social Psychology, 67(6), 1112-1125. doi:10.1037//0022-3514.67.6.1112

Larson, R. W., Csikszantmihalyi, M., \& Graef, R. (1980). Mood variability and the psychosocial adjustment of adolescents. Journal of Youth and Adolescence, 9(9), 469-490. doi:10.1177/0192513X12437708

Larson, R. W. \& Lampman-Petraitis, C. (1989). Daily Emotional States as Reported by Children and Adolescents. Child Development, 60(5), 1250-1260.

Larson, R. W., Moneta, G., Richards, M. H., \& Wilson, S. (2002). Continuity, Stability, and Change in Daily Emotional Experience across Adolescence. Child Development, 73(4), 1151-1165. doi:10.1111/1467-8624.00464

Larson, R. W. \& Richards, M. (1994). Family Emotions: Do Young Adolescents and Their Parents Experience the Same States? Journal of Research on Adolescents, 4(4), 567-583.

Lejuez, C. W., Banducci, A. N., \& Long, K. (2013). Commentary on the distress tolerance special issue. Cognitive Therapy and Research, 37(3), 510-513. doi:10.1007/s10608013-9527-2

Leyro, T. M., Zvolensky, M. J., \& Bernstein, A. (2010). Distress Tolerance and Psychopathological Symptoms and Disorders: A Review of the Empirical Literature among Adults. Psychological Bulletin, 136(4), 576-600. doi:10.1037/a0019712.Distress

Lougheed, J. P. \& Hollenstein, T. (2012). A Limited Repertoire of Emotion Regulation 
Strategies is Associated with Internalizing Problems in Adolescence. Social Development, 21(4), 704-721. doi:10.1111/j.1467-9507.2012.00663.x

McHugh, R. K., Reynolds, E. K., Leyro, T. M., \& Otto, M. W. (2013). An examination of the association of distress intolerance and emotion regulation with avoidance. Cognitive Therapy and Research, 37(2), 363-367. doi:10.1007/s10608-012-9463-6

McMahan, E. A., Choi, I., Kwon, Y., Choi, J., Fuller, J., \& Josh, P. (2015). Some Implications of Believing That Happiness Involves the Absence of Pain: Negative Hedonic Beliefs Exacerbate the Effects of Stress on Well-Being. Journal of Happiness Studies, 1-25. doi:10.1007/s10902-015-9707-8

Mitchell, J. T., Robertson, C. D., Anastopolous, A. D., Nelson-Gray, R. O., \& Kollins, S. H. (2012). Emotion dysregulation and emotional impulsivity among adults with attentiondeficit/hyperactivity disorder: Results of a preliminary study. Journal of Psychopathology and Behavioral Assessment, 34(4), 510-519. doi:10.1007/s 10862-012-9297-2

Quoidbach, J., Berry, E. V., Hansenne, M., \& Mikolajczak, M. (2010). Positive emotion regulation and well-being: Comparing the impact of eight savoring and dampening strategies. Personality and Individual Differences, 49(5), 368-373. doi:10.1016/j.paid.2010.03.048

Quoidbach, J., Mikolajczak, M., \& Gross, J. J. (2015). Positive Interventions: An Emotion Regulation Perspective. Psychological Bulletin. Advanced online publication.

Riediger, M., Schmiedek, F., Wagner, G. G., \& Lindenberger, U. (2009). Seeking Pleasure and Seeking Pain. Psychological Science, 20(12), 1-7. doi:10.1111/j.14679280.2009.02473.x

Saulsman, L. \& Nathan, P. (2012). Facing Your Feelings: Learning to Tolerate Distress. Perth, Western Australia: Center for Clinical Interventions.

Sheppes, G. \& Gross, J. J. (2012). Emotion Regulation Effectiveness: What Works When. In I. Weiner, H. A. Tennen, \& J. M. Suls (Eds.), Handbook of Psychology, Personality, and Social Psychology (2nd ed., pp. 391-403). Somerset, NJ: John Wiley \& Sons.

Sher, K. J. \& Trull, T. J. (1994). Personality and disinhibitory psychopathology: Alcoholism and antisocial personality disorder. Journal of Abnormal Psychology, 103(1), 92-102. doi:10.1037/0021-843X.103.1.92

Simons, J. S. \& Gaher, R. M. (2005). The distress tolerance scale: Development and validation of a self-report measure. Motivation and Emotion, 29(2), 83-102. doi:10.1007/s11031005-7955-3

Steinberg, L. (2005). Cognitive and affective development in adolescence. Trends in Cognitive Sciences, 9(2), 69-74. doi:10.1016/j.tics.2004.12.005 
Szasz, P. L., Szentagotai, A., \& Hofmann, S. G. (2011). The effect of emotion regulation strategies on anger. Behaviour Research and Therapy, 49(2), 114-119.

doi:10.1016/j.brat.2010.11.011

Tan, P. Z., Forbes, E. E., Dahl, R. E., Ryan, N. D., Siegle, G. J., Ladouceur, C. D., \& Silk, J. S. (2012). Emotional reactivity and regulation in anxious and nonanxious youth: A cellphone ecological momentary assessment study. Journal of Child Psychology and Psychiatry and Allied Disciplines, 53(2), 197-206. doi:10.1111/j.1469-

7610.2011.02469.x

Vandell, D. L., Belsky, J., Burchinal, M., Steinberg, L., \& Vandergrift, N. (2010). Do effects of early child care extend to age 15 years? Results from the NICHD study of early child care and youth development. Child Development, 81(3), 737-56. doi:10.1111/j.14678624.2010.01431.x

Waters, S. F. \& Thompson, R. A. (2014). Children's perceptions of the effectiveness of strategies for regulating anger and sadness. International Journal of Behavioral Development, 38(2), 174-181. doi:10.1177/0165025413515410

Webb, T. L., Miles, E., \& Sheeran, P. (2012). Dealing with feeling: A meta-analysis of the effectiveness of strategies derived from the process model of emotion regulation. Psychological Bulletin, 138(4), 775-808. doi:10.1037/a0027600

Weinberger, D. A. (1996). Distorted Self-Perceptions: Divergent Self-Reports as Statistical Outliers in the Multimethod Assessment of Children's Social-Emotional Adjustment. Journal of Personality Assessment, 66(1), 126-143.

Weinberger, D. A. \& Schwartz, G. E. (1990). Distress and restraint as superordinate dimensions of self-reported adjustment: A typological perspective. Journal of Personality, 58(2), 381-417. doi:10.1111/j.1467-6494.1990.tb00235.x

Weitzman, M. L., McHugh, R. K., \& Otto, M. W. (2011). The association between affect amplification and urgency. Depression and Anxiety, 28(12), 1105-1110. doi:10.1002/da.20830

Whiteside, S. P. \& Lynam, D. R. (2001). The five factor model and impulsivity: Using a structural model of personality to understand impulsivity. Personality and Individual Differences, 30(4), 669-689. doi:10.1016/S0191-8869(00)00064-7

Williams, L. M., Brown, K. J., Palmer, D., Liddell, B. J., Kemp, A. H., Olivieri, G., ... Gordon, E. (2006). The Mellow Years?: Neural Basis of Improving Emotional Stability over Age. Journal of Neuroscience, 26(24), 6422-6430. doi:10.1523/JNEUROSCI.0022-06.2006

Zimmer-Gembeck, M. J. \& Skinner, E. A. (2011). The development of coping across childhood and adolescence: An integrative review and critique of research. International Journal of Behavioral Development, 35(1), 1-17. doi:10.1177/0165025410384923 
Zimmermann, P. \& Iwanski, A. (2014). Emotion regulation from early adolescence to emerging adulthood and middle adulthood: Age differences, gender differences, and emotionspecific developmental variations. International Journal of Behavioral Development, 38(2), 182-194. doi:10.1177/0165025413515405

Zvolensky, M. J., Leyro, T. M., Bernstein, A., \& Vujanovic, A. A. (2010). Distress Tolerance: Theory, Research, and Clincial Applications. In M. J. Zvolensky, A. Bernstein, \& A. a. Vujanovic (Eds.), Distress Tolerance: Theory, Research, and Clincial Applications (pp. 3-27). New York, NY: Guilford Press. 
Table A1.

Bivariate Correlations and Descriptive Statistics $(N=136-137)$

$\begin{array}{llll}\text { Mean (SD) } & 1 & 2 & 3\end{array}$

1. Maladaptive ER with NA

$3.70(1.05) \quad---$

2. Adaptive ER with NA $4.52(.95) \quad-.09$

3. Maladaptive ER with PA

$2.32(.66) \quad .46^{* * *} \quad-.20^{*}$

4. Adaptive ER with PA

$-.25^{* *}$

$.51^{* * *}$

$-.24^{* *}$

4

5

6

5. Distress Tolerance

$$
3.14(.73) \quad-.29^{* * *}
$$

$-.13$

$-.22^{* *}$ $-.29^{* * *}$ $---$

6. Impulsivity

$2.41(.91)$ $.19^{*}$ $-.20^{*}$ .14 $-.10-.20^{*}$ $---$

Note. $\mathrm{ER}=$ emotion regulation. $\mathrm{NA}=$ negative affect. $\mathrm{PA}=$ positive affect. ${ }^{*} p<.05 . * * p<.01$. $* * * p<.001$. Pairwise deletion. 
Table A2.

Moderation Models

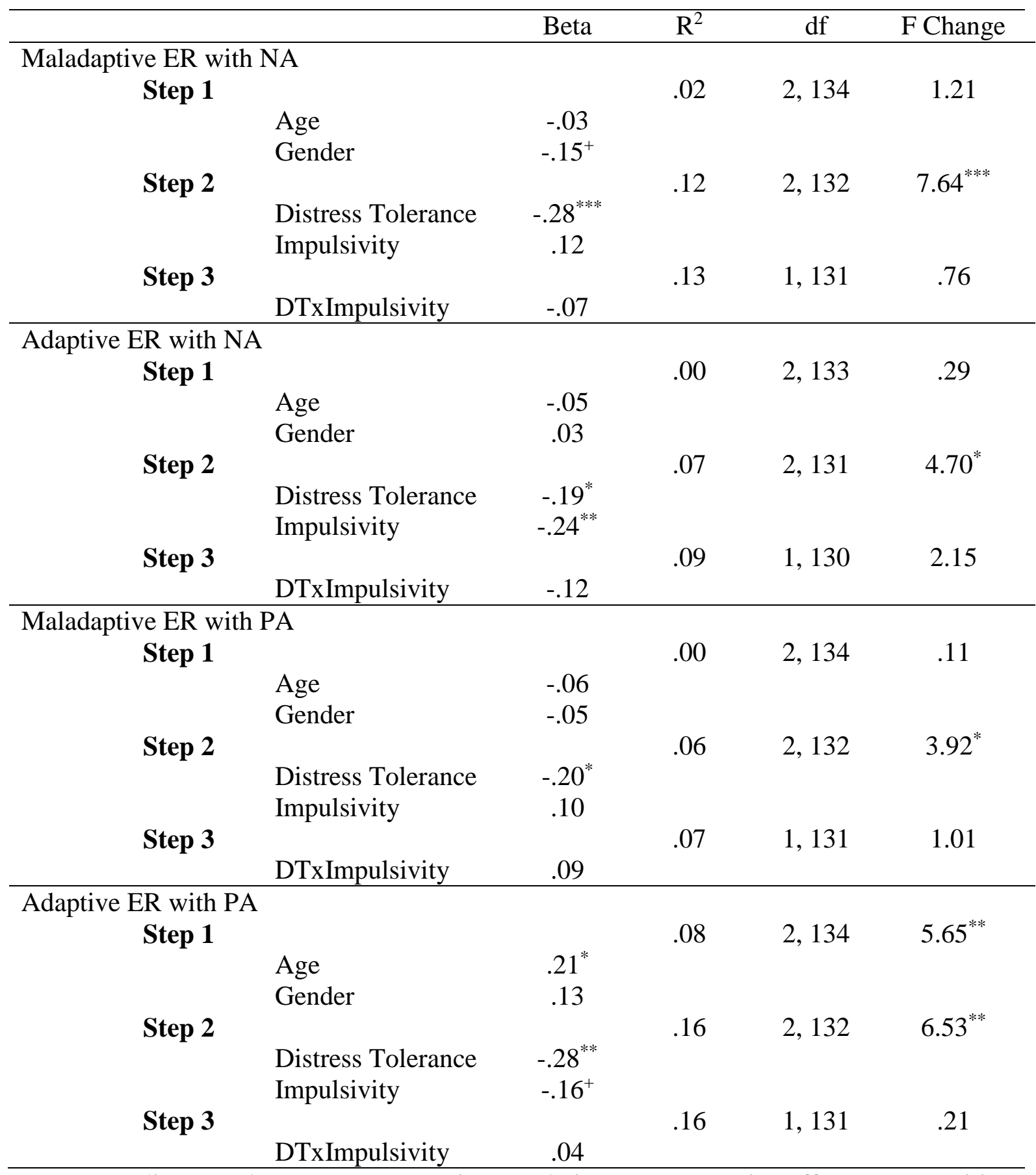

Note. $\mathrm{DT}=$ distress tolerance. $\mathrm{ER}=$ emotion regulation. $\mathrm{NA}=$ negative affect. $\mathrm{PA}=$ positive affect. Gender coded $0=$ male, $1=$ female. Beta's are from the final step of the regression. Listwise deletion. ${ }^{+} p<.08 .{ }^{*} p<.05 .{ }^{* *} p<.01 .{ }^{* * * *} p<.001$. 


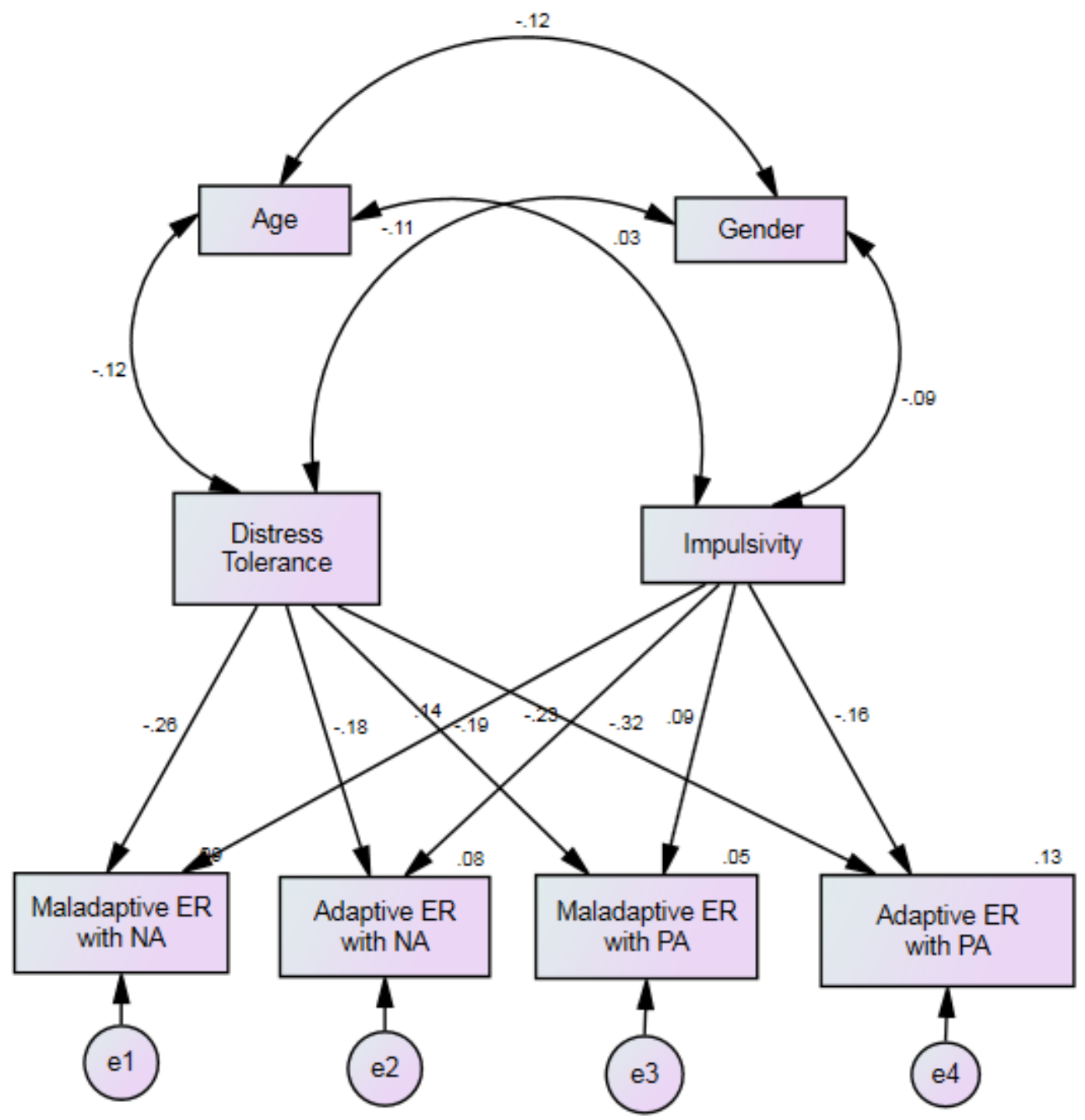

Figure A1. Proposed model: Distress tolerance and impulsivity predicting use of emotion regulation strategies with age and gender controlled. 


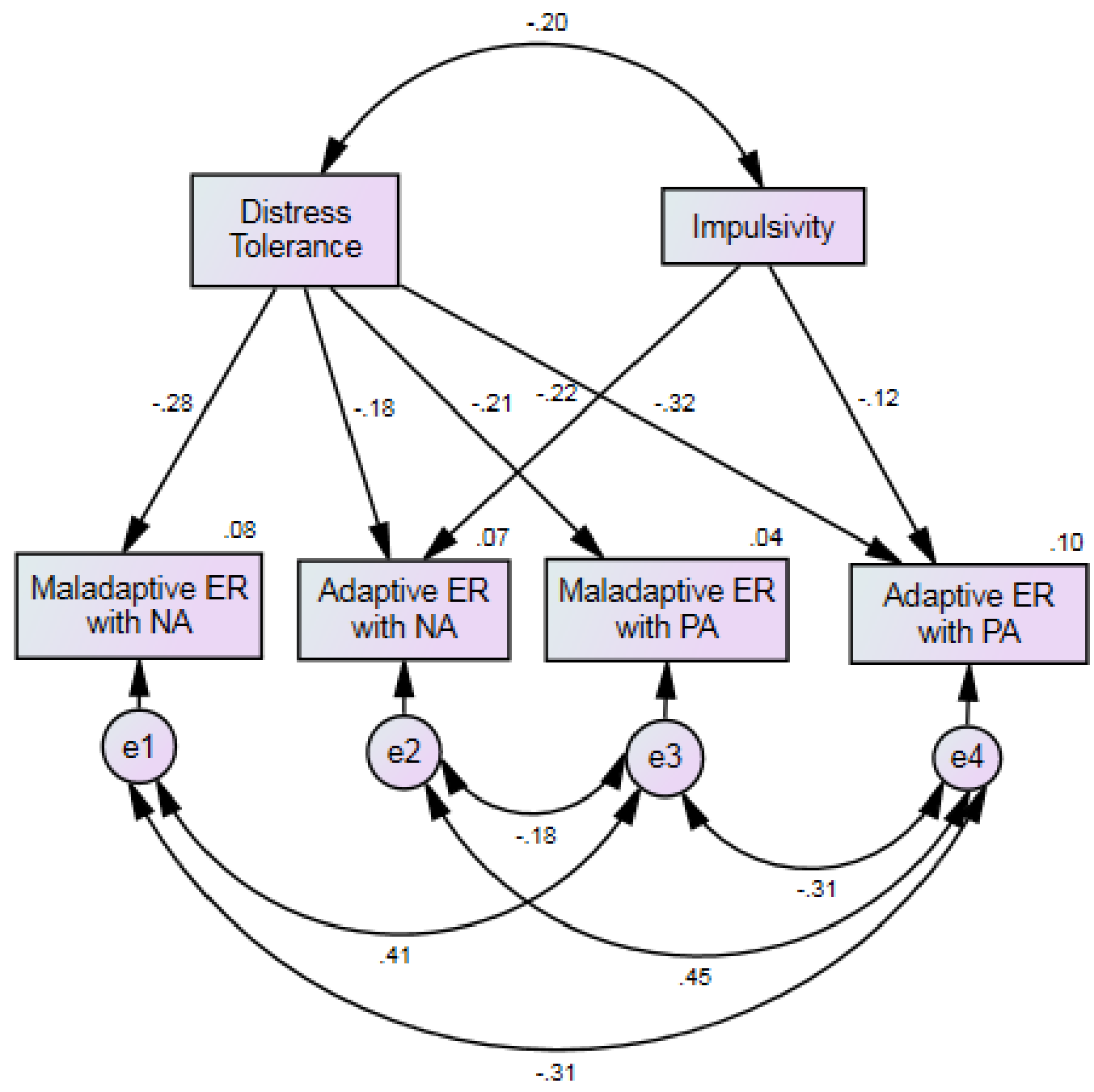

Figure A2. Trimmed model. Standardized estimates for significant associations between distress tolerance, impulsivity, and emotion regulation strategy use. 
Appendix B

Demographic Measures

Teen Reported Demographics

1. What is your sex or gender?

$$
\square \text { Male } \quad \square \text { Female }
$$

2. What is your age?
$\square 14$
15
16
17
$\square 18$

Other (please specify)

3. What is your race or ethnicity? (select all that apply)
$\square$ White or Caucasian
Asian or Asian-American
$\square$ Black or African-American
Native American
$\square$ Hispanic or Latino-American
Pacific Islander or Native Hawaiian

Other (please specify)

\section{Parent Reported Demographics about Self and Teen}

1. What is your teen's gender?
$\square$ Female
$\square$ Male

2. What is your teen's age?
$\square 14$
$\square 17$
$\square 15$
18
$\square 16$

Other (please specify)

3. What is your teen's birthdate? (so we can determine exact ages)

4. What grade is your teen in?
$\square 9^{\text {th }}$ grade
$\square 10^{\text {th }}$ grade
$11^{\text {th }}$ grade
$12^{\text {th }}$ grade 
5. What is your teen's ethnicity? (select all that apply)
White
Native-American
African-American or Black
Pacific Islander or Native Hawaiian
$\square$ Asian-American or Asian
$\square$ Other
$\square$ Hispanic or Latino

6. What is your gender?
$\square$ Male
$\square$ Female

7. What is your age?

8. What is your marital status?
$\square$ Married
Separated
$\square$ Single
$\square$ Divorced
$\square$ Living with Partner
Widowed

9. What is the highest level of education you have completed?
$\square$ Did not attend school
$\square 8^{\text {th }}$ grade or less
2-year college degree
$\square 9^{\text {th }}-11^{\text {th }}$ grade
Graduated from 4-year college
$\square$ Graduated from high school
$\square$ Some graduate school
$\square$ Some college
Completed Master's or 2-3 year graduate degree
$\square$ Completed M.D. or Ph. D.

10. What is your approximate yearly household income?

$\begin{array}{lll}\square \text { Less than } \$ 19,999 & \square \$ 80,000-99,999 & \square \$ 160,000-179,999 \\ \square \$ 20,000-39,999 & \square \$ 100,000-119,999 & \square \$ 180,000-199,999 \\ \square \$ 40,000-59,999 & \square \$ 120,000-139,999 & \square \text { Over } \$ 200,000 \\ \square \$ 60,000-79,999 & \square \$ 140,000-159,999 & \square \text { Prefer not to answer }\end{array}$


Appendix C

Questionnaire Measures

Emotion Regulation Questionnaire for Children and Adolescents

These are questions about what you feel like inside and how you show your feelings. Please indicate how much you agree or disagree with each statement.

\begin{tabular}{|c|c|c|c|c|c|c|c|}
\hline & $\begin{array}{c}\text { Strongly } \\
\text { Disagree } \\
1\end{array}$ & 2 & 3 & 4 & 5 & 6 & $\begin{array}{l}\text { Strongly } \\
\text { Agree } \\
7\end{array}$ \\
\hline $\begin{array}{l}\text { When I want to feel happier, I think about } \\
\text { something different. }\end{array}$ & $\square$ & $\square$ & $\square$ & $\square$ & $\square$ & $\square$ & $\square$ \\
\hline I keep my feelings to myself. & $\square$ & $\square$ & $\square$ & $\square$ & $\square$ & $\square$ & $\square$ \\
\hline $\begin{array}{l}\text { When I want to feel less bad (e.g., sad, } \\
\text { angry, or worried), I think about } \\
\text { something different. }\end{array}$ & $\square$ & $\square$ & $\square$ & $\square$ & $\square$ & $\square$ & $\square$ \\
\hline $\begin{array}{l}\text { When I am feeling happy, I am careful not } \\
\text { to show it. }\end{array}$ & $\square$ & $\square$ & $\square$ & $\square$ & $\square$ & $\square$ & $\square$ \\
\hline $\begin{array}{l}\text { When I'm worried about something, I } \\
\text { make myself think about it in a way that } \\
\text { helps me feel better. }\end{array}$ & $\square$ & $\square$ & $\square$ & $\square$ & $\square$ & $\square$ & $\square$ \\
\hline $\begin{array}{l}\text { I control my feelings by not showing } \\
\text { them. }\end{array}$ & $\square$ & $\square$ & $\square$ & $\square$ & $\square$ & $\square$ & $\square$ \\
\hline $\begin{array}{l}\text { When I want to feel happier about } \\
\text { something, I change the way I'm thinking } \\
\text { about it. }\end{array}$ & $\square$ & $\square$ & $\square$ & $\square$ & $\square$ & $\square$ & $\square$ \\
\hline $\begin{array}{l}\text { I control my feelings about things by } \\
\text { changing the way I think about them. }\end{array}$ & $\square$ & $\square$ & $\square$ & $\square$ & $\square$ & $\square$ & $\square$ \\
\hline $\begin{array}{l}\text { When I'm feeling bad (e.g., sad, angry, or } \\
\text { worried), I'm careful not to show it. }\end{array}$ & $\square$ & $\square$ & $\square$ & $\square$ & $\square$ & $\square$ & $\square$ \\
\hline $\begin{array}{l}\text { When I want to feel less bad (e.g., sad, } \\
\text { angry, or worried) about something, I } \\
\text { change the way I'm thinking about it. }\end{array}$ & $\square$ & $\square$ & $\square$ & $\square$ & $\square$ & $\square$ & $\square$ \\
\hline
\end{tabular}




\section{$\underline{\text { Negative Affect Regulation Strategies }}$}

Think about your responses when you are feeling upset or badly (sad, angry, worried, etc.). How much would you agree or disagree with each of the following statements?

\begin{tabular}{|c|c|c|c|c|c|c|c|}
\hline & $\begin{array}{c}\text { Strongly } \\
\text { Disagree } \\
1 \\
\end{array}$ & 2 & 3 & 4 & 5 & 6 & $\begin{array}{c}\text { Strongly } \\
\text { Agree } \\
7\end{array}$ \\
\hline $\begin{array}{l}\text { I talk to someone about my negative } \\
\text { feelings or the problem. }\end{array}$ & $\square$ & $\square$ & $\square$ & $\square$ & $\square$ & $\square$ & $\square$ \\
\hline $\begin{array}{l}\text { I avoid thinking about the problem and } \\
\text { my negative feelings. }\end{array}$ & $\square$ & $\square$ & $\square$ & $\square$ & $\square$ & $\square$ & $\square$ \\
\hline $\begin{array}{l}\text { I distract myself with an activity (TV, } \\
\text { exercise, game, book, etc.). }\end{array}$ & $\square$ & $\square$ & $\square$ & $\square$ & $\square$ & $\square$ & $\square$ \\
\hline $\begin{array}{l}\text { I keep thinking about my negative } \\
\text { feelings and how badly I feel. }\end{array}$ & $\square$ & $\square$ & $\square$ & $\square$ & $\square$ & $\square$ & $\square$ \\
\hline $\begin{array}{l}\text { I try to solve the problem that is making } \\
\text { me feel badly. }\end{array}$ & $\square$ & $\square$ & $\square$ & $\square$ & $\square$ & $\square$ & $\square$ \\
\hline $\begin{array}{l}\text { I express my negative feelings (yelling, } \\
\text { crying, hitting something, etc.). }\end{array}$ & $\square$ & $\square$ & $\square$ & $\square$ & $\square$ & $\square$ & $\square$ \\
\hline
\end{tabular}




\section{Perceived Effectiveness of Negative Affect Regulation Strategies}

Think about when you have responded in these ways when feeling UPSET or BAD. If you don't respond in these ways, try to imagine how these responses may or may not change how you feel. How would each response change how you feel when feeling UPSET or BAD?

\begin{tabular}{|c|c|c|c|c|c|}
\hline & $\begin{array}{c}\text { Makes } \\
\text { me feel } \\
\text { really } \\
\text { bad (or a } \\
\text { lot } \\
\text { worse) }\end{array}$ & $\begin{array}{l}\text { Makes } \\
\text { me feel a } \\
\text { little bad } \\
\text { or worse }\end{array}$ & $\begin{array}{c}\text { Does not } \\
\text { change } \\
\text { how I } \\
\text { feel or } \\
\text { unsure }\end{array}$ & $\begin{array}{c}\text { Makes } \\
\text { me feel a } \\
\text { little } \\
\text { good or } \\
\text { better }\end{array}$ & $\begin{array}{c}\text { Makes } \\
\text { me feel } \\
\text { really } \\
\text { good (or } \\
\text { a lot } \\
\text { better) }\end{array}$ \\
\hline I think about something different. & $\square$ & $\square$ & $\square$ & $\square$ & $\square$ \\
\hline I keep my feelings to myself. & $\square$ & $\square$ & $\square$ & $\square$ & $\square$ \\
\hline $\begin{array}{l}\text { I make myself think about it in a } \\
\text { way that makes me feel better. }\end{array}$ & $\square$ & $\square$ & $\square$ & $\square$ & $\square$ \\
\hline $\begin{array}{l}\text { I control my feelings by not showing } \\
\text { them. }\end{array}$ & $\square$ & $\square$ & $\square$ & $\square$ & $\square$ \\
\hline $\begin{array}{l}\text { I change the way I'm thinking about } \\
\text { it. }\end{array}$ & $\square$ & $\square$ & $\square$ & $\square$ & $\square$ \\
\hline $\begin{array}{l}\text { I'm careful not to show my bad } \\
\text { feelings (sad, angry, worried). }\end{array}$ & $\square$ & $\square$ & $\square$ & $\square$ & $\square$ \\
\hline $\begin{array}{l}\text { I talk to someone about my negative } \\
\text { feelings or the problem. }\end{array}$ & $\square$ & $\square$ & $\square$ & $\square$ & $\square$ \\
\hline $\begin{array}{l}\text { I avoid thinking about the problem } \\
\text { and my negative feelings. }\end{array}$ & $\square$ & $\square$ & $\square$ & $\square$ & $\square$ \\
\hline $\begin{array}{l}\text { I distract myself with an activity } \\
\text { (TV, exercise, game, book, etc.). }\end{array}$ & $\square$ & $\square$ & $\square$ & $\square$ & $\square$ \\
\hline $\begin{array}{l}\text { I keep thinking about my negative } \\
\text { feelings and how badly I feel. }\end{array}$ & $\square$ & $\square$ & $\square$ & $\square$ & $\square$ \\
\hline $\begin{array}{l}\text { I try to solve the problem that is } \\
\text { making me feel badly. }\end{array}$ & $\square$ & $\square$ & $\square$ & $\square$ & $\square$ \\
\hline $\begin{array}{l}\text { I express my negative feelings } \\
\text { (yelling, crying, hitting something, } \\
\text { etc.). }\end{array}$ & $\square$ & $\square$ & $\square$ & $\square$ & $\square$ \\
\hline
\end{tabular}




\section{Positive Affect and Responses Survey}

When you are feeling really good and happy, how likely are you to...

\begin{tabular}{|c|c|c|c|c|c|}
\hline & $\begin{array}{c}\text { Not at } \\
\text { all likely } \\
1\end{array}$ & 2 & $\begin{array}{c}\text { Somewhat } \\
\text { likely } \\
3 \\
\end{array}$ & 4 & $\begin{array}{c}\text { Very } \\
\text { likely } \\
5 \\
\end{array}$ \\
\hline $\begin{array}{l}\text { not think about your good feelings } \\
\text { much? }\end{array}$ & $\square$ & $\square$ & $\square$ & $\square$ & $\square$ \\
\hline $\begin{array}{l}\text { become physically affectionate (hug } \\
\text { someone, kiss someone, etc.)? }\end{array}$ & $\square$ & $\square$ & $\square$ & $\square$ & $\square$ \\
\hline $\begin{array}{l}\text { tell a lot of people at once how good } \\
\text { you feel (mass text, post online, etc.)? }\end{array}$ & $\square$ & $\square$ & $\square$ & $\square$ & $\square$ \\
\hline $\begin{array}{l}\text { decide that your good feelings are not } \\
\text { important? }\end{array}$ & $\square$ & $\square$ & $\square$ & $\square$ & $\square$ \\
\hline $\begin{array}{l}\text { tell a close friend or family member } \\
\text { how happy you are? }\end{array}$ & $\square$ & $\square$ & $\square$ & $\square$ & $\square$ \\
\hline $\begin{array}{l}\text { think about how things could go } \\
\text { wrong? }\end{array}$ & $\square$ & $\square$ & $\square$ & $\square$ & $\square$ \\
\hline $\begin{array}{l}\text { really try to enjoy the good feelings } \\
\text { and absorb the moment? }\end{array}$ & $\square$ & $\square$ & $\square$ & $\square$ & $\square$ \\
\hline think about how good you feel? & $\square$ & $\square$ & $\square$ & $\square$ & $\square$ \\
\hline $\begin{array}{l}\text { think about how lucky you are } \\
\text { compared to others? }\end{array}$ & $\square$ & $\square$ & $\square$ & $\square$ & $\square$ \\
\hline $\begin{array}{l}\text { express your emotions in some way } \\
\text { (smile, laugh, jump for joy, etc.)? }\end{array}$ & $\square$ & $\square$ & $\square$ & $\square$ & $\square$ \\
\hline $\begin{array}{l}\text { tell a person who seems sad or upset } \\
\text { how good you feel? }\end{array}$ & $\square$ & $\square$ & $\square$ & $\square$ & $\square$ \\
\hline $\begin{array}{l}\text { be careful not to show people how } \\
\text { happy you feel? }\end{array}$ & $\square$ & $\square$ & $\square$ & $\square$ & $\square$ \\
\hline not notice that you are happy? & $\square$ & $\square$ & $\square$ & $\square$ & $\square$ \\
\hline reflect on your good qualities? & $\square$ & $\square$ & $\square$ & $\square$ & $\square$ \\
\hline celebrate your good feelings? & $\square$ & $\square$ & $\square$ & $\square$ & $\square$ \\
\hline $\begin{array}{l}\text { mark your feelings in some way (with } \\
\text { a picture, writing about them, etc.)? }\end{array}$ & $\square$ & $\square$ & $\square$ & $\square$ & $\square$ \\
\hline be thankful? & $\square$ & $\square$ & $\square$ & $\square$ & $\square$ \\
\hline
\end{tabular}




\section{Perceived Effectiveness of Positive Affect Regulation Strategies}

Think about when you have responded in these ways when feeling GOOD or HAPPY. If you don't respond in these ways, try to imagine how these responses may or may not change how you feel. How do you think each response would change how you feel?

\begin{tabular}{|c|c|c|c|c|c|}
\hline & $\begin{array}{c}\text { Makes } \\
\text { me feel } \\
\text { really } \\
\text { bad (or a } \\
\text { lot } \\
\text { worse) }\end{array}$ & $\begin{array}{c}\text { Makes } \\
\text { me feel } \\
\text { a little } \\
\text { bad or } \\
\text { worse }\end{array}$ & $\begin{array}{l}\text { Does not } \\
\text { change } \\
\text { how I feel } \\
\text { or unsure }\end{array}$ & $\begin{array}{l}\text { Makes } \\
\text { me feel } \\
\text { a little } \\
\text { good or } \\
\text { better }\end{array}$ & $\begin{array}{c}\text { Makes } \\
\text { me feel } \\
\text { really } \\
\text { good (or } \\
\text { a lot } \\
\text { better) }\end{array}$ \\
\hline $\begin{array}{l}\text { not think about your good feelings } \\
\text { much. }\end{array}$ & $\square$ & $\square$ & $\square$ & $\square$ & $\square$ \\
\hline $\begin{array}{l}\text { become physically affectionate (hug } \\
\text { someone, kiss someone, etc.). }\end{array}$ & $\square$ & $\square$ & $\square$ & $\square$ & $\square$ \\
\hline $\begin{array}{l}\text { tell a lot of people at once how good } \\
\text { you feel (mass text, post online, etc.). }\end{array}$ & $\square$ & $\square$ & $\square$ & $\square$ & $\square$ \\
\hline $\begin{array}{l}\text { decide that your good feelings are not } \\
\text { important. }\end{array}$ & $\square$ & $\square$ & $\square$ & $\square$ & $\square$ \\
\hline $\begin{array}{l}\text { tell a close friend or family member } \\
\text { how happy you are. }\end{array}$ & $\square$ & $\square$ & $\square$ & $\square$ & $\square$ \\
\hline $\begin{array}{l}\text { think about how things could go } \\
\text { wrong. }\end{array}$ & $\square$ & $\square$ & $\square$ & $\square$ & $\square$ \\
\hline $\begin{array}{l}\text { really try to enjoy the good feelings } \\
\text { and absorb the moment. }\end{array}$ & $\square$ & $\square$ & $\square$ & $\square$ & $\square$ \\
\hline think about how good you feel. & $\square$ & $\square$ & $\square$ & $\square$ & $\square$ \\
\hline $\begin{array}{l}\text { think about how lucky you are } \\
\text { compared to others. }\end{array}$ & $\square$ & $\square$ & $\square$ & $\square$ & $\square$ \\
\hline $\begin{array}{l}\text { express your emotions in some way } \\
\text { (smile, laugh, jump for joy, etc.). }\end{array}$ & $\square$ & $\square$ & $\square$ & $\square$ & $\square$ \\
\hline $\begin{array}{l}\text { tell a person who seems sad or upset } \\
\text { how good you feel. }\end{array}$ & $\square$ & $\square$ & $\square$ & $\square$ & $\square$ \\
\hline $\begin{array}{l}\text { think about your good qualities and } \\
\text { characteristics. }\end{array}$ & $\square$ & $\square$ & $\square$ & $\square$ & $\square$ \\
\hline $\begin{array}{l}\text { careful not to show people how } \\
\text { happy you feel. }\end{array}$ & $\square$ & $\square$ & $\square$ & $\square$ & $\square$ \\
\hline not notice that you are happy. & $\square$ & $\square$ & $\square$ & $\square$ & $\square$ \\
\hline reflect on your good qualities. & $\square$ & $\square$ & $\square$ & $\square$ & $\square$ \\
\hline celebrate your good feelings. & $\square$ & $\square$ & $\square$ & $\square$ & $\square$ \\
\hline $\begin{array}{l}\text { mark your feelings in some way (with } \\
\text { a picture, writing about them, etc.). }\end{array}$ & $\square$ & $\square$ & $\square$ & $\square$ & $\square$ \\
\hline be thankful. & $\square$ & $\square$ & $\square$ & $\square$ & $\square$ \\
\hline
\end{tabular}




\section{Distress Tolerance Scale}

This section is about how you think about and experience upsetting or distressing feelings. Please tell how much you agree or disagree with the following statements.

\begin{tabular}{|c|c|c|c|c|c|}
\hline & $\begin{array}{l}\text { Strongly } \\
\text { Disagree }\end{array}$ & $\begin{array}{c}\text { Mildly } \\
\text { Disagree }\end{array}$ & $\begin{array}{l}\text { Agree } \\
\text { and } \\
\text { Disagree } \\
\text { equally }\end{array}$ & $\begin{array}{l}\text { Mildly } \\
\text { Agree }\end{array}$ & $\begin{array}{c}\text { Strongly } \\
\text { Agree }\end{array}$ \\
\hline & 1 & 2 & 3 & 4 & 5 \\
\hline $\begin{array}{l}\text { Feeling distressed or upset is } \\
\text { unbearable to me. }\end{array}$ & $\square$ & $\square$ & $\square$ & $\square$ & $\square$ \\
\hline $\begin{array}{l}\text { When I feel distressed or upset, all I } \\
\text { can think about is how bad I feel. }\end{array}$ & $\square$ & $\square$ & $\square$ & $\square$ & $\square$ \\
\hline $\begin{array}{l}\text { I can't handle feeling distressed or } \\
\text { upset. }\end{array}$ & $\square$ & $\square$ & $\square$ & $\square$ & $\square$ \\
\hline $\begin{array}{l}\text { My feelings of distress are so intense } \\
\text { that they completely take over. }\end{array}$ & $\square$ & $\square$ & $\square$ & $\square$ & $\square$ \\
\hline $\begin{array}{l}\text { There is nothing worse than feeling } \\
\text { distressed or upset. }\end{array}$ & $\square$ & $\square$ & $\square$ & $\square$ & $\square$ \\
\hline $\begin{array}{l}\text { I don't tolerate being distressed or } \\
\text { upset as well as most people. }\end{array}$ & $\square$ & $\square$ & $\square$ & $\square$ & $\square$ \\
\hline $\begin{array}{l}\text { My feelings of distress or being upset } \\
\text { are not acceptable. }\end{array}$ & $\square$ & $\square$ & $\square$ & $\square$ & $\square$ \\
\hline $\begin{array}{l}\text { I'll do anything to avoid feeling } \\
\text { distressed or upset. }\end{array}$ & $\square$ & $\square$ & $\square$ & $\square$ & $\square$ \\
\hline $\begin{array}{l}\text { Other people seem to be able to } \\
\text { tolerate feeling distressed or upset } \\
\text { better than I can. }\end{array}$ & $\square$ & $\square$ & $\square$ & $\square$ & $\square$ \\
\hline $\begin{array}{l}\text { Being distressed or upset is always a } \\
\text { major ordeal for me. }\end{array}$ & $\square$ & $\square$ & $\square$ & $\square$ & $\square$ \\
\hline $\begin{array}{l}\text { I am ashamed of myself when I feel } \\
\text { distressed or upset. }\end{array}$ & $\square$ & $\square$ & $\square$ & $\square$ & $\square$ \\
\hline $\begin{array}{l}\text { My feelings of distress or being upset } \\
\text { scare me. }\end{array}$ & $\square$ & $\square$ & $\square$ & $\square$ & $\square$ \\
\hline $\begin{array}{l}\text { I'll do anything to stop feeling } \\
\text { distressed or upset. }\end{array}$ & $\square$ & $\square$ & $\square$ & $\square$ & $\square$ \\
\hline $\begin{array}{l}\text { When I feel distressed or upset, I } \\
\text { must do something about it } \\
\text { immediately. }\end{array}$ & $\square$ & $\square$ & $\square$ & $\square$ & $\square$ \\
\hline $\begin{array}{l}\text { When I feel distressed or upset, I } \\
\text { cannot help but concentrate on how } \\
\text { bad the distress actually feels. }\end{array}$ & $\square$ & $\square$ & $\square$ & $\square$ & $\square$ \\
\hline
\end{tabular}




\section{$\underline{\text { Impulsivity (Impulse Control) }}$}

How much do you agree with each of the statements in this questionnaire about your behavior?

\begin{tabular}{|c|c|c|c|c|c|}
\hline & False & $\begin{array}{l}\text { Somewhat } \\
\text { False } \\
2\end{array}$ & Not sure & $\begin{array}{l}\text { Somewhat } \\
\text { True } \\
4\end{array}$ & True \\
\hline $\begin{array}{l}\text { I'm the kind of person who will try } \\
\text { anything once, even if it's not that } \\
\text { safe. }\end{array}$ & $\square$ & $\square$ & $\square$ & $\square$ & $\square$ \\
\hline $\begin{array}{l}\text { I should try harder to control myself } \\
\text { when I'm having fun. }\end{array}$ & $\square$ & $\square$ & $\square$ & $\square$ & $\square$ \\
\hline $\begin{array}{l}\text { I do things without giving them } \\
\text { enough thought. }\end{array}$ & $\square$ & $\square$ & $\square$ & $\square$ & $\square$ \\
\hline $\begin{array}{l}\text { I become 'wild and crazy' and do } \\
\text { things other people might not like. }\end{array}$ & $\square$ & $\square$ & $\square$ & $\square$ & $\square$ \\
\hline $\begin{array}{l}\text { If someone does something I really } \\
\text { don't like, I yell at them about it. }\end{array}$ & $\square$ & $\square$ & $\square$ & $\square$ & $\square$ \\
\hline $\begin{array}{l}\text { When I'm doing something fun (like } \\
\text { partying or acting silly), I tend to get } \\
\text { carried away and take it too far. }\end{array}$ & $\square$ & $\square$ & $\square$ & $\square$ & $\square$ \\
\hline $\begin{array}{l}\text { I say the first thing that comes to } \\
\text { mind without thinking enough about } \\
\text { it. }\end{array}$ & $\square$ & $\square$ & $\square$ & $\square$ & $\square$ \\
\hline $\begin{array}{l}\text { I stop and think things through } \\
\text { before I act. }\end{array}$ & $\square$ & $\square$ & $\square$ & $\square$ & $\square$ \\
\hline
\end{tabular}

